\title{
Cobalt based functional inorganic materials: Electrocatalytic water oxidation
}

\author{
OLIVIA BASU, SUBHABRATA MUKHOPADHYAY and SAMAR K DAS*(B) \\ School of Chemistry, University of Hyderabad, Hyderabad, Telangana 500 046, India \\ E-mail: skdas@uohyd.ac.in
}

MS received 23 March 2018; revised 13 April 2018; accepted 18 May 2018; published online 12 July 2018

\begin{abstract}
Water splitting is considered to be one of the most promising sources of sustainable energy, as it can produce hydrogen $\left(\mathrm{H}_{2}\right)$ fuel. To have successful water splitting in a sustained manner, it is necessary to develop efficient and robust catalysts that can perform water oxidation, the bottleneck process of water splitting either electrochemically or photochemically. Here, we have presented a brief descriptive analysis of different aspects of designing such catalysts in connection with our recent works on the same field. The focus of the article is to discuss contemporary works in the field of designing cobalt-based heterogeneous water oxidation electrocatalysts. To the best of our knowledge, although cobalt is the most extensively studied 1st row transition metal for water oxidation catalysis reaction, no such report has been found where the simplest cobalt complex, $\left[\mathrm{Co}\left(\mathrm{H}_{2} \mathrm{O}\right)_{6}\right]^{2+}$, has been employed as a water oxidation catalyst. Not only that, reports of cobalt-based simple and small molecular catalysts are also not very frequent. With the help of our recent works, we have tried to detail here a wide aspect of the study on cobalt-based simple and small molecular catalysts, starting from the reasons behind the scarcity of such water oxidation catalysts, to development of new ideas addressing the challenges in utilization of such small cobalt complexes for water oxidation catalyst. Here, we have addressed the scope of encapsulation chemistry in designing robust and efficient heterogeneous water oxidation catalysts using cobalt-based small molecular guest species. With the help of structural insight, gained from the recent results, we published in the field of water oxidation catalysis; here, we try to formulate a general approach that can help to prepare water oxidation catalyst based on host-guest chemistry. The article critically evaluates our recent results in connection with the approach of addressing the problem.
\end{abstract}

Keywords. MOF encapsulation; cobalt mononuclear aqua complex; zeolite-Y; $\alpha-\mathrm{Co}(\mathrm{OH})_{2}$ nano-film; ZIF-8; cobalt-centred Keggin POM; electrocatalyst; water oxidation; kinetic analysis.

\section{Introduction}

In Nature, the process for harnessing energy from sunlight is known as photosynthesis. The light energy obtained from the Sun is used to oxidize water molecules to oxygen, and the four protons and electrons, released in the process, are then spatially separated from each other. The protons and electrons enter into the separate chain of reactions, and eventually participate in the reduction of carbon dioxide, to produce glucose. ${ }^{1}$ Thus, solar energy is ultimately stored in the chemical bonds of sugar molecules, through the process of photosynthesis. Splitting of water molecules plays a pivotal role in this overall process since successful storage of solar

\footnotetext{
*For correspondence
}

energy largely depends upon its utilization in splitting water molecules and consequently generate energized and spatially separated protons and electrons. Water electrolysis, in which an external electrical potential difference is applied to split water molecules at the two electrodes of an electrochemical cell can be thought of as resembling the photosynthetic splitting of water molecules. ${ }^{2}$ The only difference being that in photosynthesis, the solar energy is converted to chemical energy, while in electrocatalytic water splitting in the electrochemical cell, the electrical energy does the job directly. Biomimetic water splitting (photocatalytic or electrocatalytic) ultimately liberates hydrogen as the product, which can be a viable source of energy.

For the past few centuries, we have become heavily reliant on coal and fossil fuels for most of our energy 
In aqueous acidic solution $(\mathrm{pH} \leq 7)$ :

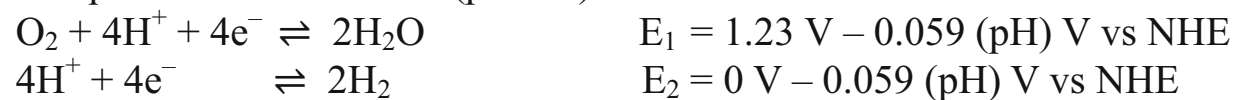

$$
\mathrm{E}_{\text {reaction }}=\mathrm{E}_{2}-\mathrm{E}_{1}=-1.23 \mathrm{~V}
$$

In aqueous basic solution $(\mathrm{pH}>7)$ :

$$
\begin{array}{ll}
\mathrm{O}_{2}+2 \mathrm{H}_{2} \mathrm{O}+4 \mathrm{e}^{-} & \rightleftharpoons 4 \mathrm{OH}^{-} \\
4 \mathrm{H}_{2} \mathrm{O}+4 \mathrm{e}^{-} & \rightleftharpoons 2 \mathrm{H}_{2}+4 \mathrm{OH}^{-}
\end{array}
$$

$$
\mathrm{E}_{3}=+0.40 \mathrm{~V}+0.059(\mathrm{pOH}) \mathrm{V} \text { vs NHE }
$$$$
\mathrm{E}_{4}=-0.83 \mathrm{~V}+0.059(\mathrm{pOH}) \mathrm{V} \text { vs NHE }
$$

$$
\mathbf{E}_{\text {reaction }}=\mathrm{E}_{4}-\mathrm{E}_{3}=-1.23 \mathrm{~V}
$$

For the reaction $2 \mathrm{H}_{2} \mathrm{O} \rightarrow 2 \mathrm{H}_{2}+\mathrm{O}_{2}$

Scheme 1. Half-cell reactions involved in water splitting in acidic (eqs. 1 and 2) and basic (eqs. 3 and 4) pH.

demands and while it took eons of photosynthesis to form the stores of fossil fuels we have today $;^{3}$ on the other hand, it will take only a few decades to deplete them all, if we go by the present rate of increase of power consumption on Earth $(\sim 13.5 \mathrm{TW}$ in 2001 , which is expected to be doubled by 2050 and tripled by 2100$).{ }^{4}$ Moreover, this large-scale consumption of fossil fuels, in this relatively short time span, has detrimental effects on the environment, like increased levels of carbon dioxide in the atmosphere leading to global warming and climatic changes. So, the need of the hour is to shift to some other source of energy which is efficient, sustainable as well as environment-friendly. ${ }^{3,4}$ Generation of hydrogen from water, in this regard, can be envisioned as a promising solution.

Water splitting process fundamentally comprises of two half-cell reactions i.e., oxidation of $\mathrm{H}_{2} \mathrm{O}$ or $\mathrm{OH}^{-}$at anode (eqs. 1 and 3 in Scheme 1) and reduction of $\mathrm{H}^{+}$or $\mathrm{H}_{2} \mathrm{O}$ at cathode (eqs. 2 and 4$) .{ }^{5}$ The nature of cathodic and anodic reactions depends on concentration of $\mathrm{H}^{+}$ and $\mathrm{OH}^{-}$ions in aqueous solution. Depending on $\mathrm{pH}$ (acidic or basic), the concentration of the more abundant species $\left(\mathrm{H}^{+} / \mathrm{OH}^{-}\right)$in aqueous solution varies, and so, the overall water splitting process follows different fundamental reactions (Scheme 1).

A closer look at the cathodic and anodic processes shows that the redox process actually taking place at anode in basic $\mathrm{pH}$, is oxidation of hydroxyl ion (equation 3); but by convention, it is called water oxidation. Similarly, in acidic medium, the cathodic process ideally can be better termed as proton reduction, while it is also conventionally known as the water reduction step. As mentioned in Scheme 1, the Nernstian potential of overall water splitting is independent of $\mathrm{pH}$, but the potential for individual half-cell reactions are $\mathrm{pH}$ dependent. Thus, we find that the process of water oxidation is more favourable in basic $\mathrm{pH}$, while the process of water reduction is easier in acidic $\mathrm{pH}$. This implies that $\mathrm{pH}$ dependence of water oxidation (WO) and water reduction (WR) reactions are opposite to each other.

The water oxidation reaction (eqs. 1 and 3 ) is the bottleneck step for the overall process of water splitting since it is the thermodynamically and kinetically most challenging step. The oxygen-oxygen double bond formed in this step cannot compensate the energy required to split equivalent number (two) of $\mathrm{O}-\mathrm{H}$ bonds. ${ }^{6}$ This ultimately results in high thermodynamic energy demand for water oxidation. The elementary steps for water oxidation (eqs. 1 and 3 ) involve the formation of several intermediates by the simultaneous liberation of electrons and protons. In most of the cases, the mechanism followed comes under the class of proton-coupled electron transfer (PCET) reaction. ${ }^{7,8}$ The overall reaction needs liberation of four protoncoupled electrons. Generally, this multistep PCET is accompanied by sequential $\mathrm{O}-\mathrm{H}$ bond breaking to finally form an $\mathrm{O}-\mathrm{O}$ bond. All of these tend to follow a sluggish reaction kinetics, thereby increasing the reaction barrier, making this process kinetically slow, which is manifested in the form of high overpotential. ${ }^{1}$ The term, overpotential can be defined as the additional potential above the thermodynamic potential which needs to be applied, to cross the reaction kinetic barrier and drive the reaction at a given rate. These two factors i.e., high Nernstian potential and high overpotential requirement combined together, makes the overall process of water oxidation both thermodynamically and kinetically uphill. ${ }^{1}$ Thus, one needs to develop an electrocatalyst that can perform this process with low overpotential and high efficiency. In addition to it, the catalyst should be robust enough to operate in a sustainable fashion in harsh conditions of electrochemical water oxidation. ${ }^{4} \mathrm{~A}$ large number of research groups have been working to obtain catalysts that fulfil these criteria. 
Both homogeneous and heterogeneous catalysts have been employed for electrochemical and photochemical water oxidation, with an aim to mimic the photosynthetic water splitting. Now, in many cases, homogeneous water oxidation catalysts (particularly inorganic coordination complexes), are found to be prone towards deactivation in the high oxidising environment of electrochemical water oxidation. Under such conditions, these complexes may undergo side reactions like ligand oxidation, which can subsequently lead to its degradation. ${ }^{1}$ Most of the heterogeneous catalysts (metal oxides, spinels, polyoxometalates, nanoparticles, etc.) on the other hand, can withstand high oxidising environment and are relatively stable under similar working/operating conditions. In addition to it, heterogeneous catalysts can be easily recovered after catalytic cycles $^{5,9}$ and can be directly implemented in device fabrication. ${ }^{10-14}$ Comparing all these aspects, we can say that, both homogeneous and heterogeneous catalysts have their own share of advantages; while most of the homogeneous catalysts have low over potential and high turnover frequency (TOF), majority of the heterogeneous catalysts are robust in nature, more user friendly and can be easily implemented in practical applications. Thus, there is a constant effort to combine the benefits of the two, by designing heterogeneous catalysts with low overpotential and high turnover frequency.

The quest for stable water oxidation catalysts with low overpotential, led the scientists of the early $20^{\text {th }}$ century to transition-metal oxides of ruthenium, iridium and platinum. ${ }^{1}$ But the use of these costly metals as catalysts limits their large-scale practical applications. In this regard, first row transition metal complexes of Groups 7, 8 and 9 serve as a storehouse of huge potential. Among these, cobalt has received immense importance in the last few years and there has been a great deal of research surrounding it. Plenty of molecular complexes with cobalt and macrocyclic ligands (porphyrin, corrole, phthalocyanine, etc.) have been reported in recent times to perform electrocatalytic WO in homogeneous as well as in heterogeneous mode. ${ }^{15-20}$ Different research groups have tried to explore the catalytic efficiency of these complexes towards electrochemical WO and have also studied the effects of the ligand environment on their WOC behaviour. ${ }^{19-21}$ Hangman porphyrin-based cobalt complexes were some of the macrocyclic ligand based cobalt complexes that showed reasonable robustness and efficiency. ${ }^{15}$ It was established by Takashi and coworkers ${ }^{19}$ that, higher the number of electron withdrawing groups attached to the porphyrin/corrolederived ligands, less will be the chances of oxidative degradation of the complex during electrochemical WO catalysis and better will be the efficiency.
Considerable progress has also been achieved in the field of mixed metal oxides, polyoxometalate type of inorganic acids and spinals based WOC in recent times. Different groups all over the world have reported polyoxometalate based WOC where the cobalt-containing active catalytic center is sandwiched between metaloxo cluster units of polyoxometalate. ${ }^{22,23}$ As mentioned earlier, most of these WOCs are stable under anodic potential and are reported to have high TOF accompanied by low operational overpotential. Most of the polyoxometalate based WOCs follow fast water oxidation reaction kinetics as a result of the scope of quick electron transfer due to its complete inorganic structure. On the other hand, parallel works with other polyoxometalate systems have established them to perform photocatalytic WO with high efficiency. ${ }^{24}$ The major drawbacks that all these systems often suffer are the chances of the catalysts undergoing irreversible transformations to heterogeneous metal oxide $\left(\mathrm{CoO}_{\mathrm{x}}\right)$ in an oxidizing environment. ${ }^{25,26}$ If $\mathrm{WO}$ is carried out in basic $\mathrm{pH}$, the chance of metal oxide/hydroxide formation becomes even higher under the application of anodic potential. Under such conditions, it is found that in many cases, the WO catalysis is actually being carried out by in situ generated metal oxide and not by the parent metal complex or polyoxometalate. In such cases, the parent compounds serve as mere precursors to the catalysts, instead of being the true catalyst. Plenty of such reports were published in the past few years where the compound which was earlier claimed to be the true catalyst, was later confirmed otherwise. ${ }^{25-27}$ In this regard, it is worth mentioning that scientists have also developed materials based on cobalt oxide for electrochemical WO. ${ }^{28-32}$ Nowadays, it is well accepted that different forms of cobalt-oxides and cobalt-hydroxides can also perform as electrochemical WOC. The efficiency of such $\mathrm{CoO}_{\mathrm{x}} / \mathrm{Co}(\mathrm{OH})_{\mathrm{x}}$ system depends largely on the morphology of the system, particle size and operational $\mathrm{pH} .{ }^{33}$ Since such materials are all heterogeneous catalysts, these are easier to work with and thus have been able to attract a lot of attention in the recent years. At the same time, these results have raised questions about the authenticity and importance of many molecular compounds which were earlier proposed to be the true catalyst. On the other hand, the major drawbacks of cobalt oxide $\left(\mathrm{CoO}_{\mathrm{x}}\right)$ as a WOC are (a) it is not stable in low $\mathrm{pH}$ under anodic potential, (b) often requires application of high overpotential for facile WO, (c) in many cases the catalytic efficiency of $\mathrm{CoO}_{x}$ has also been found to decrease rapidly with increasing operational time period. In the last few years, many heterogeneous systems have been developed which can catalyse not only water oxidation reaction but also can facilitate 
proton reduction or oxygen reduction reaction. ${ }^{20,21,34-37}$ Meanwhile, some research groups reported remarkable self-healing catalyst for heterogeneous $\mathrm{WO},{ }^{38}$ thin films containing active compound for WO, graphene and silica supported metal complexes with enhanced activity towards water splitting, $\mathrm{TiO}_{2}$ based efficient catalysts for photocatalytic $\mathrm{WO}^{39-41}$ and, robust and efficient metal organic frameworks (MOFs) and covalent organic frameworks (COFs) for catalytic water oxidation. ${ }^{42-44}$ In order to contribute to this growing field of contemporary research, Das and coworkers ${ }^{45}$ developed a heterogeneous WOC by encapsulating a manganese dimeric complex inside a MOF. Their approach was highly impressive because such encapsulation can lead to enhanced stability as well as modifications in the microenvironment of the guest species, i.e., the active complex. Similar host-guest compound based water oxidation was also reported by $\mathrm{Xu}$ and co-workers. ${ }^{46}$ Though in the last few decades, almost 20000 articles were published, that deal with the issues related to water oxidation, still the search for an efficient and robust catalyst continues.

There are numerous cobalt complexes that have been examined for WO catalytic properties, and the most inexpensive and easily available cobalt complex that comes to our mind is cobalt(II)chloride hexahydrate $\left[\mathrm{Co}\left(\mathrm{H}_{2} \mathrm{O}\right)_{6}\right] \mathrm{Cl}_{2}$. However, the free metal salt has some limitations in being used as a potential water oxidation catalyst. In case of metal complexes, the catalytic water oxidation cycle starts from $\mathrm{M}-\mathrm{OH}_{2}$ and the intermediates which are most commonly formed during OER are, $\mathrm{M}-\mathrm{OH}$ and $\mathrm{M}=\mathrm{O}$. Most of the cobalt-based WO catalysts also follow a similar pathway (Scheme 2).

In most of the cases, the formation of $\left[\mathrm{Co}^{\mathrm{IV}}=\mathrm{O}\right]$ is a necessary step for cobalt-based molecular complexes to function as a water oxidation catalyst. In most of the cases, $\left[\mathrm{Co}^{\mathrm{IV}}=\mathrm{O}\right]$ is the catalytically active species, which is responsible for water oxidation (liberation of a proton-coupled electron from water) and formation of $\mathrm{O}-\mathrm{O}$ bond. On applying oxidative potential to an aqueous solution of cobalt(II) hexahydrate complex, the $\mathrm{Co}^{\mathrm{II}}$ goes to $\mathrm{Co}^{\mathrm{III}}$ oxidation state resulting in an increase in Lewis acidity of the metal center. This eases the removal of a proton from the coordinated water on

$$
\begin{aligned}
& {\left[\mathrm{Co}^{\mathrm{II}}-\mathrm{OH}_{2}\right]^{2+} \rightleftharpoons\left[\mathrm{Co}^{\mathrm{III}}-\mathrm{OH}\right]^{2+}+\mathrm{H}^{+}+\mathrm{e}^{-}} \\
& {\left[\mathrm{Co}^{\mathrm{III}}-\mathrm{OH}\right]^{2+} \rightleftharpoons\left[\mathrm{Co}^{\mathrm{IV}}=\mathrm{O}\right]^{2+}+\mathrm{H}^{+}+\mathrm{e}^{-}}
\end{aligned}
$$

Scheme 2. Initial steps of water oxidation catalysis followed by most of the CoII based water oxidation catalysts. application of further anodic potential. But the complex thus formed i.e., $\left[\mathrm{Co}^{\mathrm{III}}-\mathrm{OH}\right]$ undergoes polymerization and precipitates out from the homogeneous solution. ${ }^{47}$ The resulting product is inactive towards water oxidation. If the polymerization step of the reaction could be stopped in some way, such that the cobalt centre of the intermediate $\left[\mathrm{Co}^{\mathrm{III}}-\mathrm{OH}\right]$ can go to its higher oxidation state under the application of positive potential, cobalt(II) hexahydrate complex might prove to be electrochemically active towards water oxidation. The polymerization reaction is shown below in Scheme 3.

Metal-organic frameworks (MOFs) can serve to be good host materials for active guest molecules owing to their well-defined void spaces. In recent times, we have been exploring cobalt-based functional materials including MOFs, polyoxometalates (POMs) and zeolites for electrochemical water oxidation. ${ }^{33,48,49}$ The present article describes our recent findings on electrochemical water oxidation catalysed by these cobaltbased materials, which were presented in the MTICXVII meeting, held in Pune during December 11-14, 2017.

\section{Electrochemical water oxidation catalysed by cobalt-based materials}

\subsection{Electrocatalyst: a mononuclear Co(II)-aqua-DMF complex trapped inside the void space of a MOF}

We have been working on metal-organic frameworks (MOFs) with flexible organic linkers ${ }^{50,51}$ and in this journey, we synthesised a Co-based MOF, $\left[\left\{\mathrm{Co}_{3}\left(\mu_{3}-\mathrm{OH}\right)(\mathrm{BTB})_{2}(\mathrm{dpe})_{2}\right\}\right.$ $\left.\left\{\mathrm{Co}\left(\mathrm{H}_{2} \mathrm{O}\right)_{4}(\mathrm{DMF})_{2}\right\}_{0.5}\right]_{\mathrm{n}} \cdot \mathrm{nH}_{2} \mathrm{O}(\mathbf{C o}-\mathbf{W O C}-1)$, using $\left[\mathrm{CoCl}_{2}\right.$. $\left.6 \mathrm{H}_{2} \mathrm{O}\right], \mathrm{H}_{3} \mathrm{BTB}$ and dpe $\left[\mathrm{H}_{3} \mathrm{BTB}=1,3,5\right.$-benzenetribenzoic acid; dpe $=1,2$-di(4-pyridyl)ethylene] as the starting material in water/DMF $\left(\mathrm{H}_{2} \mathrm{O}: \mathrm{DMF}=6: 4\right)$ at $120{ }^{\circ} \mathrm{C}$ under solvothermal conditions. ${ }^{48}$ The crystal structure of the composite shows that a $\mathrm{Co}^{\mathrm{II}}$ complex cation $\left\{\mathrm{Co}\left(\mathrm{H}_{2} \mathrm{O}\right)_{4}(\mathrm{DMF})_{2}\right\}^{2+}$ is encapsulated in the void space of the MOF and surprisingly, it is not coordinated to the framework, giving rise to a hostguest supramolecular system (Figure 1). In the composite, the guest molecule is situated between two interpenetrated frameworks, such that it cannot come out of the framework unless the framework is destroyed. The situation can be compared to a ship $\left\{\mathrm{Co}\left(\mathrm{H}_{2} \mathrm{O}\right)_{4}(\mathrm{DMF})_{2}\right\}^{2+}$ in a bottle (the rigid MOF framework), where the ship cannot come out of the bottle unless the bottle is broken. As a result, the complex $\left\{\mathrm{Co}\left(\mathrm{H}_{2} \mathrm{O}\right)_{4}(\mathrm{DMF})_{2}\right\}^{2+}$ can interact with its surrounding through pores of the MOF but does not leach out through them.

As the MOF is insoluble in common solvents, all the electrochemical measurements were performed in a heterogeneous manner. All electrochemical experiments were per- 


$$
\begin{aligned}
& {\left[\mathrm{Co}^{\mathrm{II}}-\mathrm{OH}_{2}\right]^{2+} \rightleftharpoons\left[\mathrm{Co}^{\mathrm{III}}-\mathrm{OH}\right]^{2+}+\mathrm{H}^{+}+\mathrm{e}^{-}} \\
& {\left[\mathrm{Co}^{\mathrm{III}}-\mathrm{OH}\right]^{2+}+\left[\mathrm{Co}^{\mathrm{III}}-\mathrm{OH}\right]^{2+} \rightarrow\left[\mathrm{Co}^{\mathrm{III}}-\mathrm{O}-\mathrm{Co}^{\mathrm{III}}\right]^{4+}+\mathrm{H}_{2} \mathrm{O} \rightarrow \mathrm{ppt} .}
\end{aligned}
$$

Scheme 3. Polymerization reaction of $\left[\mathrm{Co}^{\mathrm{II}}\left(\mathrm{H}_{2} \mathrm{O}\right)_{6}\right]^{2+}$ under oxidizing environment.

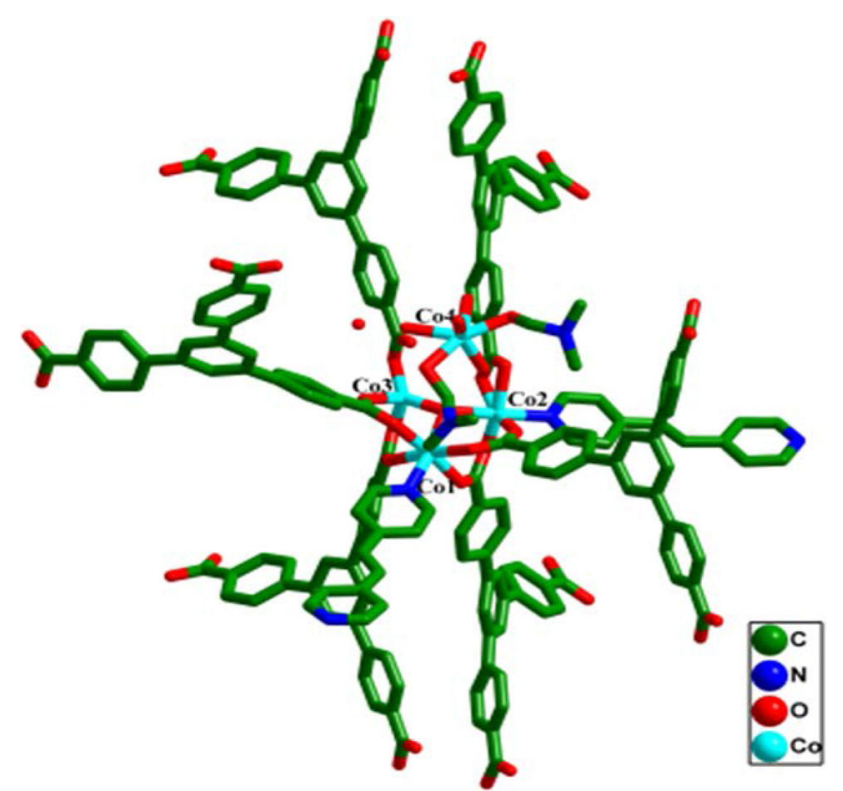

Figure 1. Active site structure of Co-WOC-1. Adapted from the work of Manna et al. ${ }^{48}$

formed using a three-electrode electrochemical cell employing Co-WOC-1-modified glassy carbon as working, homemade $\mathrm{Ag} / \mathrm{AgCl}(3 \mathrm{M})$ as reference and $\mathrm{Pt}$-wire as counter electrodes. For the preparation of Co-WOC-1-modified electrode, $8 \mathrm{mg}$ of Co-WOC-1 and $2 \mathrm{mg}$ of acetylene black carbon were taken in $2 \mathrm{~mL} \mathrm{EtOH}: \mathrm{H}_{2} \mathrm{O}$ (3:2) mixture and to it $20 \mu \mathrm{L} 5 \mathrm{wt} \%$ nafion (aq) was added. The mixture was kept in sonication to make a homogeneous suspension and $10 \mu \mathrm{L}$ of this mixture was coated on glassy carbon electrode having $3 \mathrm{~mm}$ diameter (geometrical area $=0.0706 \mathrm{~cm}^{2}$ ) resulting in $40 \mu \mathrm{g}$ sample Co-WOC-1 on glassy carbon electrode. The same loading on the electrode surface was maintained for all electrochemical experiments unless otherwise stated. The electrode was dried under IR-lamp (temperature $\sim 70{ }^{\circ} \mathrm{C}$ ) prior to use. All the experiments were performed at an ambient temperature and electrode potentials were converted to the NHE scale using the relation $\mathrm{E}(\mathrm{NHE})=\mathrm{E}(\mathrm{Ag} / \mathrm{AgCl})+$ $0.197 \mathrm{~V}$ when the $\mathrm{Ag} / \mathrm{AgCl}$ electrode was used as the standard electrode. CV scans were initiated at the open circuit potential (OCP) and the anodic side was scanned first followed by a cathodic scan. Three cycles were taken consecutively for each set of CV measurements in quiescent solution. Unless specified otherwise, all the measurements were recorded with $100 \mathrm{mV} / \mathrm{s}$ scan rate.

The cyclic voltammogram of Co-WOC-1 obtained in $0.1 \mathrm{M} \mathrm{KOH}$ showed one quasi-reversible couple (A1/C1). This couple $\left(\mathrm{E}_{\mathrm{A} 1}=0.41 \mathrm{~V}, \mathrm{E}_{\mathrm{C} 1}=0.32 \mathrm{~V}\right.$ and $\mathrm{E}_{1 / 2}=$
$0.37 \mathrm{~V}$ vs. NHE) can be attributed to the oxidation of $\mathrm{Co}^{\mathrm{II}} \rightarrow$ $\mathrm{Co}^{\mathrm{III}}$. When $\mathrm{pH}$ of the electrolyte solution was lowered from pH 13 (0.1 M KOH) to pH 8 (phosphate buffer), the positions of peaks shifted to less anodic side. The plot of peak potential $\left(\mathrm{Co}^{\mathrm{II}} \rightarrow \mathrm{Co}^{\mathrm{III}}\right)$ versus $\mathrm{pH}$ hence derived from the cyclic voltammetric measurements, conducted in different pHs, shows a linear dependence with a slope of $121 \mathrm{mV} / \mathrm{pH}$. As suggested by the work of Meyer and co-workers, ${ }^{52,53}$ such a dependence of peak potential in the case of electrochemical water oxidation can only be a result of PCET taking place. According to Nernst equation (Scheme 4, eq. 5), a slope of $121 \mathrm{mV} / \mathrm{pH}$ can be expected in case of a two proton-coupled one electron transfer $\left(1 \mathrm{e}^{-} / 2 \mathrm{H}^{+}\right)$process. There is a second broader peak (A2, Figure $2 \mathrm{a})\left(\mathrm{E}_{\mathrm{A} 2}=0.71 \mathrm{~V}\right.$ vs. NHE) followed by a sharp onset of current. This onset of current is due to the surge of electrons, characteristic of water oxidation (eqs. 1 and 3 ). The peak A2 can be ascribed to the oxidation of $\mathrm{Co}^{\mathrm{III}} \rightarrow \mathrm{Co}^{\mathrm{IV}}$ (most probably $\mathrm{Co}^{\mathrm{IV}}=\mathrm{O}$ ), which as has already been discussed, is the active species for splitting of $\mathrm{O}-\mathrm{H}$ bond and formation of $\mathrm{O}-\mathrm{O}$ bond, during water oxidation.

To check the electrochemical stability of Co-WOC-1, it was subjected to 1000 cycles of cyclic voltammetric scans in $0.1 \mathrm{M} \mathrm{KOH}$. There is a very small drop in catalytic current (ca. $19 \mu \mathrm{A}$ ) for the $1000^{\text {th }}$ cycle as compared to the $2^{\text {nd }}$ cycle. The drop in current is due to the loss of sample from the electrode surface due to oxygen bubble evolution. A similar inference could also be drawn from ICP-AES analysis of the electrolyte, which did not show any detectable trace of cobalt in it. This proves that the framework of the catalyst remains intact under the harsh operational conditions since there was no leaching of cobalt into the solution. Both these results prove the durability of the composite Co-WOC-1, as an electrochemical water oxidation catalyst.

This further motivated us to study the kinetic aspect of the electrocatalyst. Galvanostatic iR-corrected Tafel plots were constructed for different $\mathrm{pHs}$ of the electrolyte solution. Overpotential $(\eta)$ at $1 \mathrm{mAcm}^{-2}$ current density was calculated from the Tafel plots at different $\mathrm{pHs}$. The minimum value of overpotential (at $1 \mathrm{mAcm}^{-2}$ current density) was found to be $390 \mathrm{mV}$ at $\mathrm{pH} 13(0.1 \mathrm{M} \mathrm{KOH})$. Corresponding Tafel plot gave a linear dependence between overpotential $(\eta)$ and catalytic current density with a slope of $128 \mathrm{mV} /$ decade (Figure $2 \mathrm{~b}$ ). The catalyst also showed a high turnover frequency of $0.05 \mathrm{~s}^{-1}$.

Quantitative estimation of the amount of oxygen evolved was measured using gas chromatography and Faradaic efficiency was calculated to be $96 \%$. Low Tafel slope along with moderate overpotential (at $1 \mathrm{mAcm}^{-2}$ current density) of the catalyst and high Faradaic efficiency, confirms Co-WOC-1 
For a reaction of the type: $\mathbf{A}+\mathbf{m} \mathbf{H}^{+}+\mathbf{n e}^{-} \rightarrow \mathbf{B}$

$>$ According to Nernst Equation $\mathrm{E}=\mathrm{E}^{0}-\frac{2.303 \times m R T}{n F} \times p H$

$\checkmark$ Case I $\mathrm{m}=1, \mathrm{n}=1, \mathrm{E}=\mathrm{E}^{0}-0.059 \mathrm{pH}$

$\checkmark$ Case II $\mathrm{m}=2, \mathrm{n}=1, \mathrm{E}=\mathrm{E}^{0}-0.118 \mathrm{pH}$

Scheme 4. Derivation of the relation between the slope of the plot of $\mathrm{pH} v s$. peak potential and the number of protons-electrons involved in a PCET process from Nernst equation.
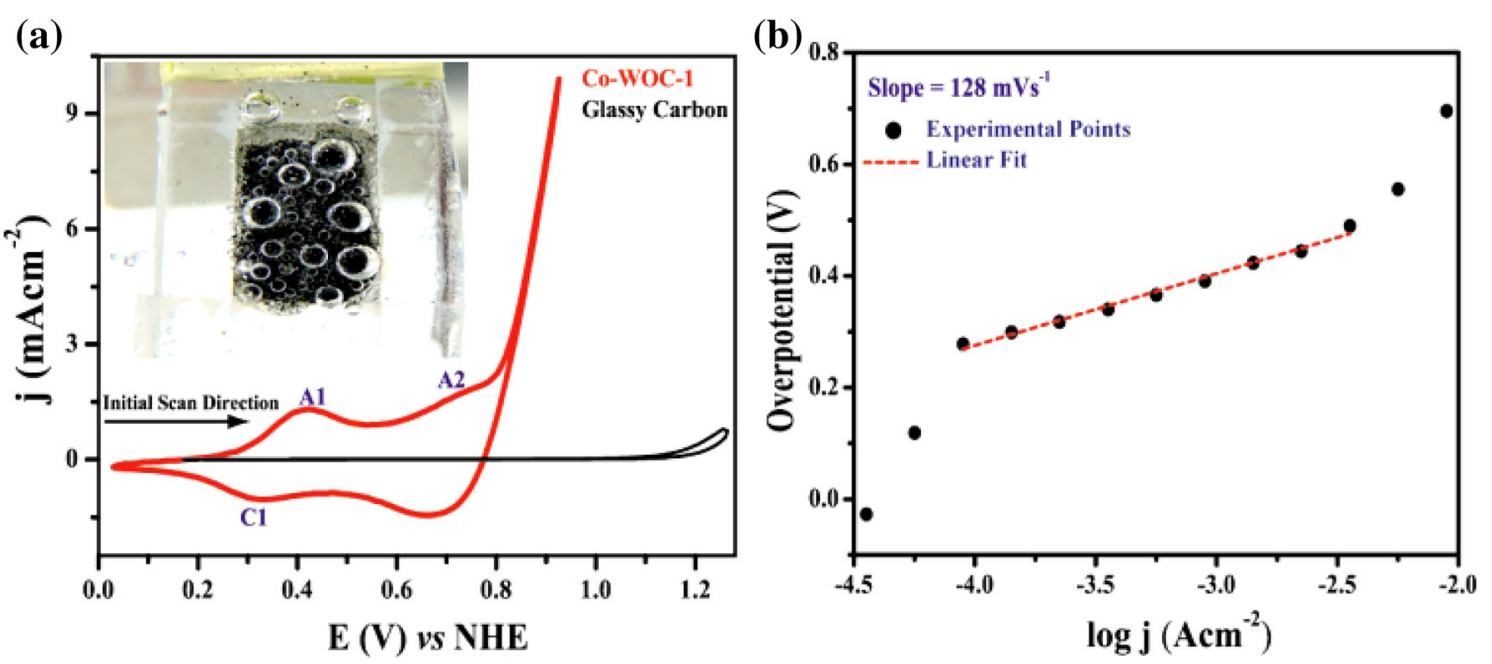

Figure 2. (a) Cyclic voltammograms of Co-WOC-1 (red line) coated on glassy carbon electrode (3 mm diameter) in $0.1 \mathrm{M} \mathrm{KOH} \mathrm{(pH} \mathrm{13)} \mathrm{at} \mathrm{scan} \mathrm{rates} \mathrm{of} 100 \mathrm{mVs}^{-1}$ and the profile for glassy carbon electrode (black line). Inset: Photograph of an FTO electrode coated with Co-WOC-1 during electrolysis showing $\mathrm{O}_{2}$ bubbles. (b) Galvanostatic iR corrected Tafel plot of Co-WOC-1 at pH 13. Adapted from the work of Manna et al. ${ }^{48}$

as an efficient water oxidation catalyst. During this study, one important observation was that, when we performed the electrochemical experiments on Co-WOC-1 at pH 4 (or a lower $\mathrm{pH})$, there was no redox response corresponding to $\mathrm{Co}^{\mathrm{II}} / \mathrm{Co}^{\mathrm{III}}$ couple and so, the characteristic onset of current for OER was also absent. One probable reason for the same can be coordination by $\mathrm{OH}^{-}$ions in basic solution (pH 13) to the active $\mathrm{Co}^{\mathrm{II}}$ center which is not possible in acidic solution ( $\mathrm{pH} 4$ and lower) due to the dominance of $\mathrm{H}^{+}$ion concentration instead of $\mathrm{OH}^{-}$ ion concentration in low $\mathrm{pH}$. In basic $\mathrm{pH}, \mathrm{OH}^{-}$ion coordinates to the active $\mathrm{Co}^{\mathrm{II}}$ center, which enhances the electron density around cobalt center and hence, helps in the oxidation of cobalt center $\left(\mathrm{Co}^{\mathrm{II}} \rightarrow \mathrm{Co}^{\mathrm{III}}\right)$. Besides, the increased electron-rich environment around the cobalt center, stabilizes the higher valent intermediate species; thereby facilitating the fundamental reactions of water oxidation.

Now, one can argue about the role of cobalt ions present in the framework, in the catalysis of water oxidation, but, it can be reasoned well (described below) that it is the cobalt ion of the entrapped cobalt complex and not the framework of the host that is responsible for such catalytic behaviour of the composite. The entrapped cobalt complex has four labile water molecules and two disordered DMF molecules as ligands. While the cobalt centers of the framework are strongly coordinated to oxygens of $\mathrm{BTB}\left[\mathrm{H}_{3} \mathrm{BTB}=1,3,5\right.$ benzenetribenzoic acid] and nitrogens of dpe ligands [dpe = 1, 2-di(4-pyridyl)ethylene]. From this bonding scheme, we find that the four labile water molecules coordinated to the mononuclear cobalt complex can undergo easy substitution. But, the ligands coordinated to the framework cobalt centers are strongly bound chelating ligands and cannot be easily substituted. Thus, during water oxidation, the preferable position for binding of $\mathrm{OH}^{-}$should be the mononuclear cobalt complex $\left\{\mathrm{Co}\left(\mathrm{H}_{2} \mathrm{O}\right)_{4}(\mathrm{DMF})_{2}\right\}^{2+}$. Furthermore, if $\mathrm{OH}^{-}$would have bound to cobalt centers of the framework, the system would have broken down just after a few electrocatalytic cycles. But instead, we were able to achieve 1000 catalytic cycles. Thus, we can safely say that it is the entrapped mononuclear cobalt complex $\left\{\mathrm{Co}\left(\mathrm{H}_{2} \mathrm{O}\right)_{4}(\mathrm{DMF})_{2}\right\}^{2+}$, which is acting as the active species for oxidation of water molecules.

In fine, we can say that Co-WOC-1 demonstrates a unique example of a water oxidation catalyst from a structural point 

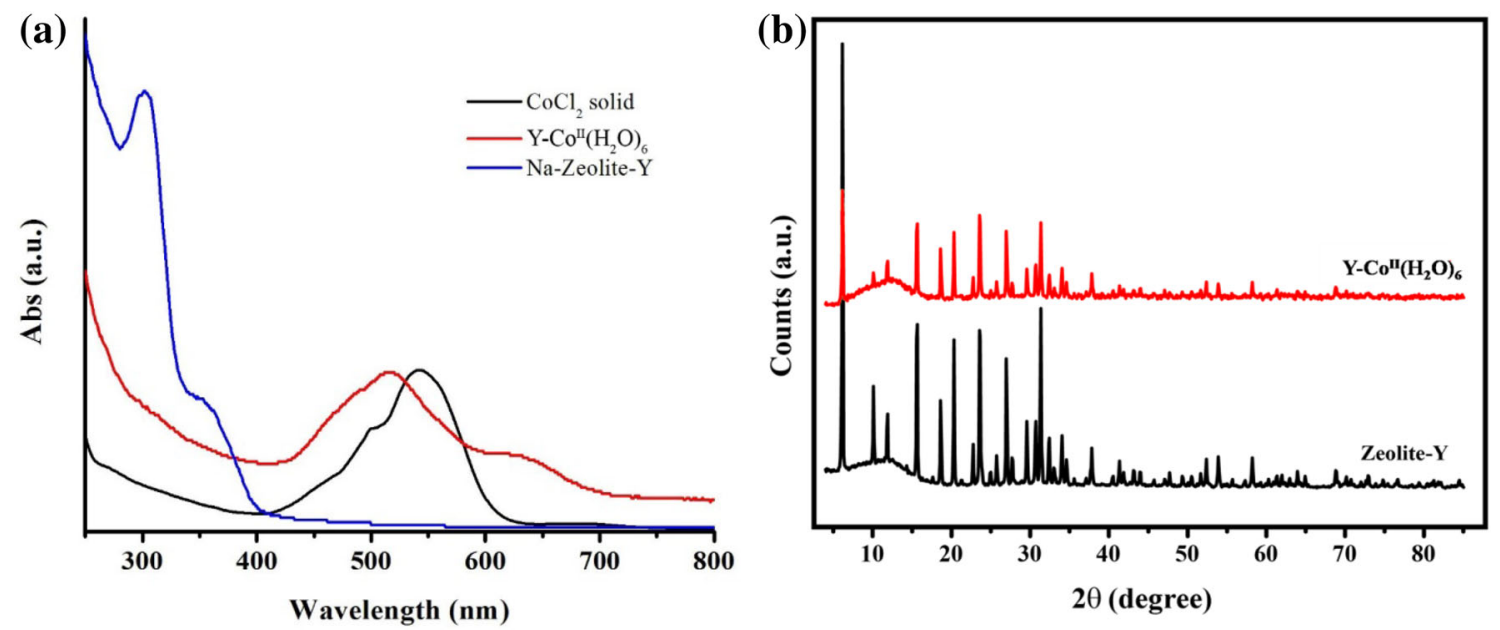

Figure 3. (a) UV-Vis (DRS) spectra of $\mathrm{CoCl}_{2} \cdot 6 \mathrm{H}_{2} \mathrm{O}$ (solid), $\mathrm{Y}-\mathrm{Co}^{\mathrm{II}}\left(\mathrm{H}_{2} \mathrm{O}\right)_{6}$ and Zeolite-Y; (b) PXRD patterns of Zeolite-Y and $\mathbf{Y}-\mathbf{C o}^{\mathbf{I I}}\left(\mathbf{H}_{2} \mathbf{O}\right)_{6}$. Reproduced from the work of Bose et al. ${ }^{33}$

of view. Even though it operates best in high $\mathrm{pH}$, it has very good TOF and high Faradaic efficiency. The catalyst is much stable so as to retain its efficiency even after 1000 cycles. Taking all the points into consideration, this piece of work certainly leaves some scope for improvement. Developing robust catalysts in a cost-effective way, which can perform water oxidation catalysis in neutral/low $\mathrm{pH}$ with low overpotential and high TOF is required for practical usage. Co-WOC1 performs WO with high efficiency but, only operates in less desirable basic $\mathrm{pH}$. Besides, it requires less economic solvothermal methods for its synthesis. Considering all these points, it can be said that Co-WOC-1 has provided us with the much needed structural insight to prepare novel WOC but requires attention regarding the factors, mentioned above, for large scale usage.

\subsection{Electrocatalyst: $\alpha-\mathrm{Co}(\mathrm{OH})_{2}$ nanofilm in-situ generated on the zeolite-Y surface}

Since we have claimed in the preceding section that it is the mono-nuclear cobalt(II)-aqua coordination complex that is solely responsible for the electrocatalytic water oxidation, we thought of encapsulating $\left[\mathrm{Co}^{\mathrm{II}}\left(\mathrm{H}_{2} \mathrm{O}\right)_{6}\right]^{2+}$ as such inside zeolite- $\mathrm{Y}$ and then investigate its WOC properties in order to rationalize our finding. The choice of zeolite as the host material can be owed to their high chemical and thermal stability. Zeolite-Y is a well-known microporous aluminosilicate zeolite composed of $\left\{\mathrm{AlO}_{4}\right\}^{5-}$ and $\left\{\mathrm{SiO}_{4}\right\}^{4-}$ tetrahedra which gives it its characteristic thermal stability (thermal decomposition at $793^{\circ} \mathrm{C}$ ). Zeolite-Y contains two kinds of cavities within its framework: sodalite cage of $\approx 5 \AA$ diameter with access through $\approx 2.5 \AA$ windows and the super cage of $\approx 13 \AA$ diameter with access through $\approx 7.4 \AA$ windows. The negative charges of the framework are balanced by the positive charges of the cations $\left(\mathrm{Na}^{+}, \mathrm{K}^{+}, \mathrm{Ca}^{2+}\right)$ present in non-framework positions (cavities and channels), which are generally mobile and can be exchanged with other metal ions by means of ion exchange mechanism. ${ }^{54}$

This property of the material was used for preparing cobalt exchanged zeolite-Y, Y-Co ${ }^{\mathbf{I I}}\left(\mathbf{H}_{2} \mathbf{O}\right)_{6}$ where two $\mathrm{Na}^{+}$ ions were exchanged by one $\mathrm{Co}^{2+}$ ion. Successful metal ion exchange could be realized from the colouration of the Y-Co ${ }^{\text {II }}\left(\mathbf{H}_{2} \mathbf{O}\right)_{6}$ species in comparison to zeolite-Y. From UVVis (DRS) (Figure 3a) spectra of the two, it can further be confirmed. The light pink colour of the composite confirms the octahedral coordination of cobalt ion (i.e., $\mathrm{Co}^{\mathrm{II}}\left(\mathrm{H}_{2} \mathrm{O}\right)_{6}$ encapsulated in zeolite-Y). Comparison of the PXRD patterns of zeolite-Y and Y-Co ${ }^{\mathbf{I I}}\left(\mathbf{H}_{2} \mathbf{O}\right)_{6}$ (cobalt exchanged zeolite) reveals that the zeolite-framework remains intact even after the exchange of hetero-ion (Figure $3 b$ ).

Then, we went on to conduct electrochemical studies on this composite as well in alkaline $\mathrm{pH}$ and the results indicated Y-Co ${ }^{\text {II }}\left(\mathbf{H}_{2} \mathbf{O}\right)_{6}$ to be a better WOC than our previously reported composite (Co-WOC-1). But when we ion-exchanged the pink coloured Y-Co ${ }^{\mathbf{I I}}\left(\mathbf{H}_{2} \mathbf{O}\right)_{6}$ with $1 \mathrm{M}$ $\mathrm{NaCl}$ aqueous solution, the $\mathrm{Co}^{\mathrm{II}}$ ions came out of zeolite-Y cages resulting in pink coloration of the aqueous solution, whereas the composite $\mathbf{Y}-\mathbf{C o}^{\mathbf{I I}}\left(\mathbf{H}_{2} \mathbf{O}\right)_{6}$ went back to its parent off-white coloured zeolite-Y form. It is quite likely because supercages of $\approx 13 \AA$ diameter are accessible through $\approx 7.4 \AA$ windows/pores, through which $\left[\mathrm{Co}\left(\mathrm{H}_{2} \mathrm{O}\right)_{6}\right]^{2+}$ complex cation can easily come out of the framework since the molecular diameter of $\left[\mathrm{Co}\left(\mathrm{H}_{2} \mathrm{O}\right)_{6}\right]^{2+}$ is around $4.5 \AA$. Apart from that, the size consideration suggests that the supercage can include two $\left[\mathrm{Co}^{\mathrm{II}}\left(\mathrm{H}_{2} \mathrm{O}\right)_{6}\right]^{2+}$ species, which on oxidation can form the inactive dimeric species (eq. 8) in the supercage resulting in a loss of catalytic activity. However, no $\mathrm{Co}^{2+}$ ions came out from $\mathbf{Y}-\mathbf{C o}^{\mathbf{I I}}\left(\mathbf{H}_{2} \mathbf{O}\right)_{6}$ coated on the electrode, used in the electrochemical cell at $\mathrm{pH} 13$. We then investigated on the nature of the material coated on the electrode which was actually performing the role of the catalyst, affording efficient oxygen evolution. Field emission scanning electron micrograph (FESEM) images of zeolite-Y and 

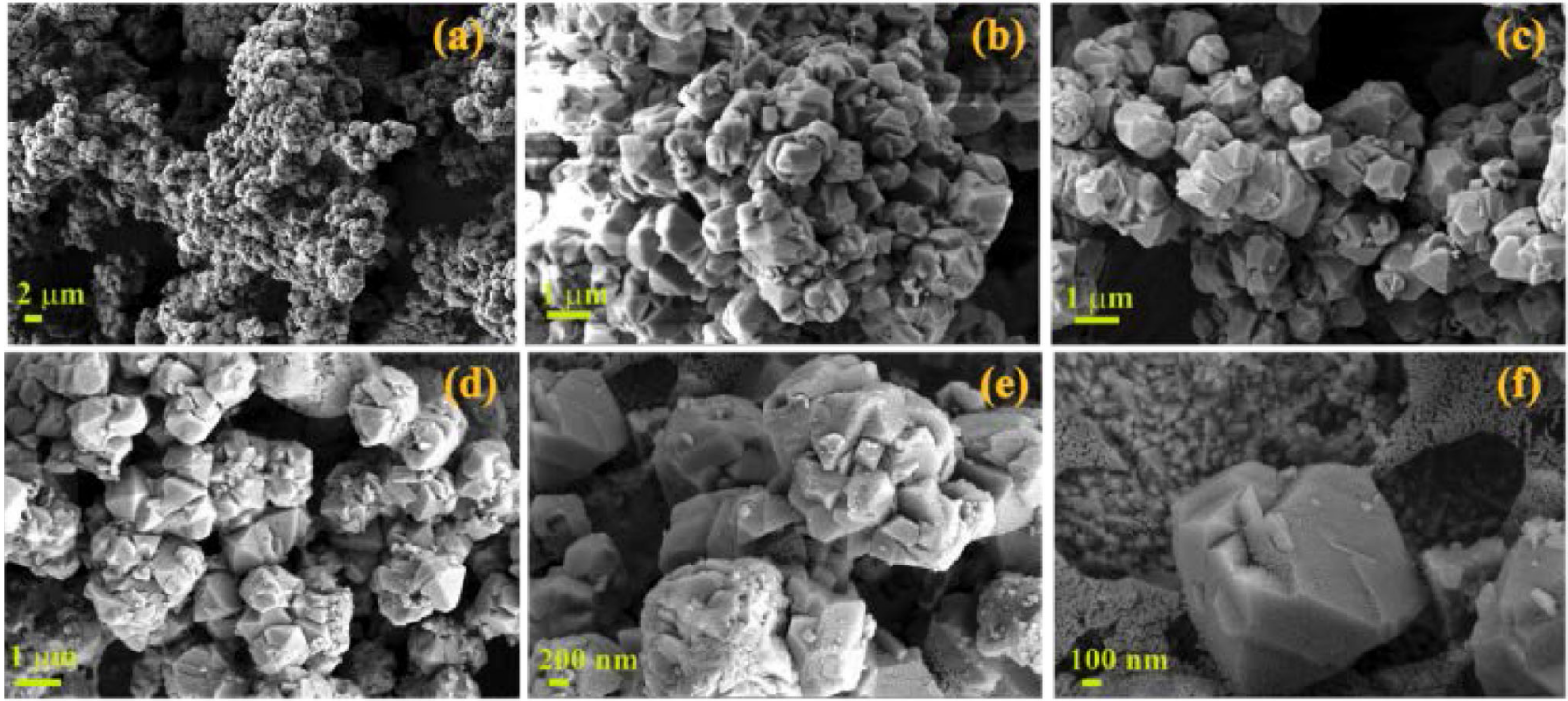

Figure 4. FESEM micrographs of (a-c) Zeolite- $\mathrm{Y}$ and $(\mathrm{d}-\mathrm{f}) \mathrm{Y}-\mathrm{Co}^{\mathrm{II}}\left(\mathrm{H}_{2} \mathrm{O}\right)_{6}$; all samples were prepared from their respective coated films on a glass plate using $0.5 \mathrm{wt} \%$ nafion as a binder. Reproduced from the work of Bose et al. ${ }^{33}$
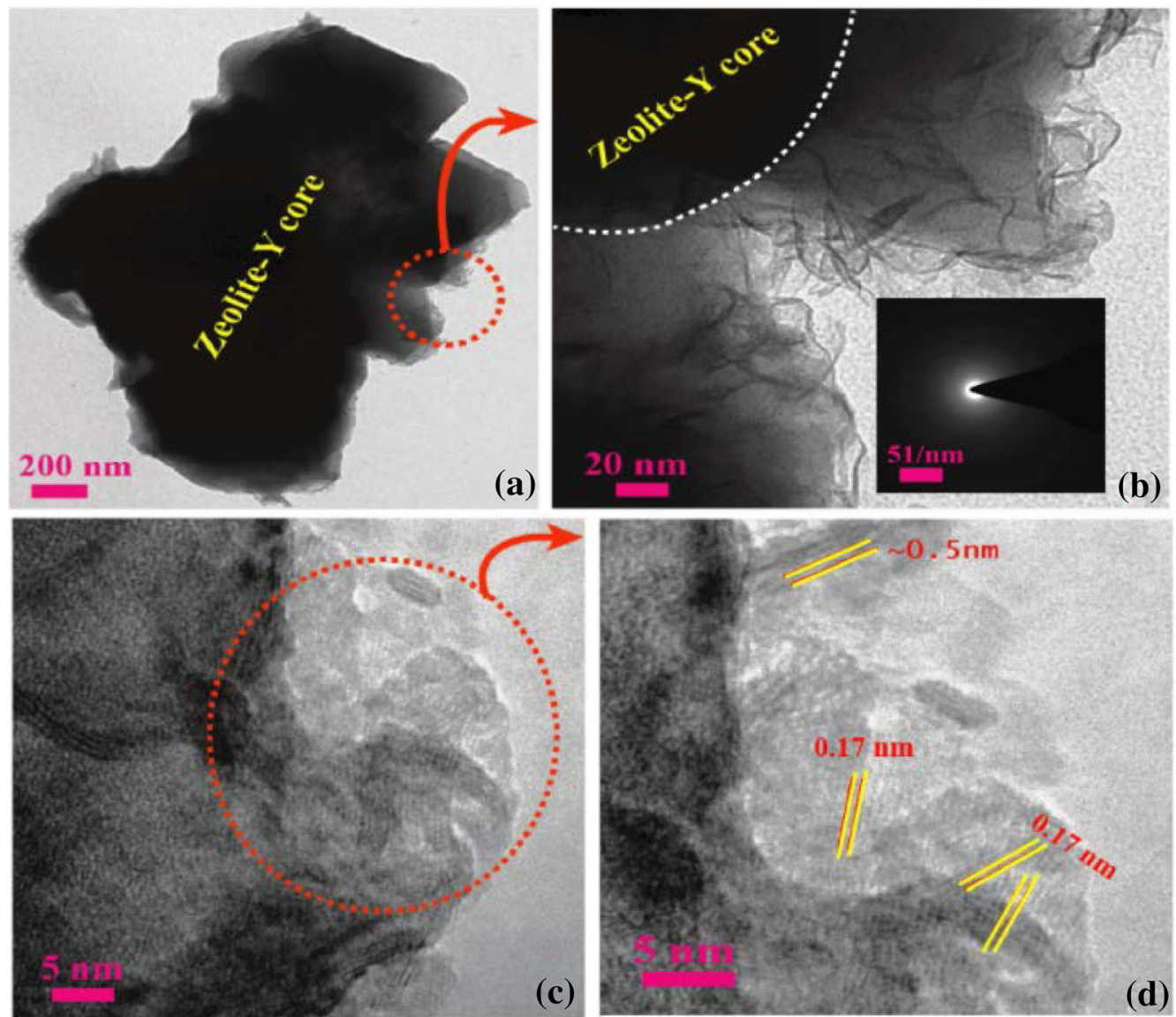

Figure 5. TEM micrographs of (a-d) $\mathbf{Y}-\boldsymbol{\alpha}-\mathbf{C o}(\mathbf{O H})_{2}$ collected from the coating on a glass plate using $0.5 \mathrm{wt} \%$ nafion; inset of (b) is the SAED pattern. Reproduced from the work of Bose $e t$ $a l .{ }^{33}$

Y-Co ${ }^{\text {II }}\left(\mathbf{H}_{2} \mathbf{O}\right)_{6}$ showed similar features, with zeolite crystals (size $1 \mu \mathrm{m}$ ) having a smooth surface (Figure 4). But, when the $\mathbf{Y}-\mathbf{C o}^{\mathbf{I I}}\left(\mathbf{H}_{2} \mathbf{O}\right)_{6}$ film was dipped in $0.1 \mathrm{M} \mathrm{KOH}$ solution for
$10 \mathrm{~min}$, the uniform surface of the zeolite became corrugated and a cabbage type morphology formed on zeolite particles (Figure 5). 
A similar type of morphology was previously observed for $\alpha-\mathrm{Co}(\mathrm{OH})_{2}$ deposited on carbon nanotubes and $\mathrm{Ag}$ nanowires. ${ }^{55-57}$ So, in this case, also, the morphology was suspected to be due to the formation of $\mathrm{Co}(\mathrm{OH})_{2}$ film on zeolite surface. The TEM micrographs of these samples also confirmed the formation of ultrathin nano-sheets of $\alpha$ $\mathrm{Co}(\mathrm{OH})_{2}$ covering the surface of zeolite-Y (Figure 5).

Since $\alpha-\mathrm{Co}(\mathrm{OH})_{2}$ film/sheet formed only on dipping Y$\mathrm{Co}^{\mathrm{II}}\left(\mathrm{H}_{2} \mathrm{O}\right)_{6}$ into $\mathrm{KOH}$ solution, it can be inferred that $\mathrm{Co}^{\mathrm{II}}$ ions were expelled from zeolite due to ion exchange with $\mathrm{K}^{+}$ ions and it further precipitated out as $\alpha-\mathrm{Co}(\mathrm{OH})_{2}$ film/sheet on the zeolite-Y surface. All these results helped us to unambiguously say that it is $\alpha-\mathrm{Co}(\mathrm{OH})_{2}$, which is the actual catalyst in this case.

The electrochemical studies were performed in $0.1 \mathrm{M} \mathrm{KOH}$ (pH 13) by coating a mixture of $\mathbf{Y}-\mathbf{C o}^{\mathbf{I I}}\left(\mathbf{H}_{2} \mathbf{O}\right)_{6}$ and carbon on the electrode surface (vide supra). The cyclic voltammogram (Figure 6) reveals two successive one electron oxidation peaks (A1, A2). The peak (A1) at $0.39 \mathrm{~V}$ and the broad oxidation peak (A2) at $0.74 \mathrm{~V}$ can be attributed to the oxidation of $\mathrm{Co}^{\mathrm{II}} \rightarrow \mathrm{Co}^{\mathrm{III}}$ and $\mathrm{Co}^{\mathrm{III}} \rightarrow \mathrm{Co}^{\mathrm{IV}}$, respectively. These peaks are followed by a sharp increase in current corresponding to water oxidation. A complete analysis of the redox couples $(\mathrm{A} 1 / \mathrm{C} 1)$ and $(\mathrm{A} 2 / \mathrm{C} 2)$ suggests that the redox processes are taking place from surface bound redox active species and most probably $\mathrm{Co}^{\mathrm{IV}}\left(\mathrm{Co}^{\mathrm{IV}}=\mathrm{O}\right)$ is the intermediate for water oxidation.

Stability of the composite was studied by recording 2000 cycles of cyclic voltammetric scans and the current drop between $2^{\text {nd }}$ and $2000^{\text {th }}$ cycle was very negligible $(\sim 34 \mu \mathrm{A})$. PXRD patterns of $\mathbf{Y}-\boldsymbol{\alpha}-\mathrm{Co}(\mathrm{OH})_{2}$ taken before and after 1000 cyclic voltammetric scans matched well with each other confirming that the zeolite framework is stable under the employed electrolytic conditions. We even compared the activity of our catalyst $\mathbf{Y}-\alpha-\mathrm{Co}(\mathrm{OH})_{2}$ with its $\beta$ polymorph, i.e., $\mathrm{Y}-\beta-\mathrm{Co}(\mathrm{OH})_{2}$ under similar working condition $(0.1 \mathrm{M}$

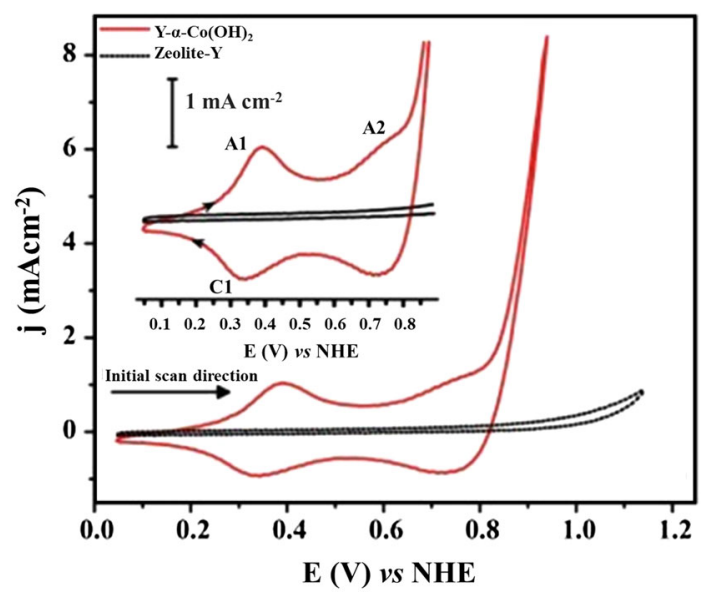

Figure 6. Cyclic voltammogram of $\mathbf{Y}-\alpha-$ $\mathbf{C o}(\mathbf{O H})_{2}$; inset is the enlarged portion of the corresponding voltammogram from 0.1 to $0.8 \mathrm{~V}$. Adapted from the work of Bose et al. ${ }^{33}$
$\mathrm{KOH}$ ) and found that our catalyst is much more active as far as water oxidation is concerned. ${ }^{33}$

The Tafel polarization plot (Tafel plot) for $\mathrm{Y}-\alpha-\mathrm{Co}(\mathrm{OH})_{2}$ shows linearity for a wide range of current density with a slope as low as $59 \mathrm{mV} /$ decade, suggesting very fast oxygen evolution kinetics in this medium. The respective overpotential $(\eta)$ at $1 \mathrm{~mA} / \mathrm{cm}^{2}$ as deduced from the Tafel plot was found to be $329 \mathrm{mV}$ in $0.1 \mathrm{M} \mathrm{KOH}$. Turnover frequency (TOF) at $1 \mathrm{~mA} / \mathrm{cm}^{2}$ current density (at $\eta=329 \mathrm{mV}$ ) is $0.35 \mathrm{~mol}$ $\mathrm{O}_{2}(\mathrm{~mol} \mathrm{Co})^{-1} \mathrm{~s}^{-1}$ in $0.1 \mathrm{M} \mathrm{KOH}$. Our catalyst was found to be much more efficient than other $\mathrm{Co}(\mathrm{OH})_{2}$ based electrocatalysts when considering the high TOF of the material. Faradaic efficiency of the catalyst was found to be $92 \%$ in $0.1 \mathrm{M} \mathrm{KOH}$.

So, in our journey, we developed a unique methodology to generate a highly active electrocatalyst $\mathbf{Y}-\boldsymbol{\alpha}-\mathbf{C o}(\mathbf{O H})_{2}$ by in situ synthesis from $\mathbf{Y}-\mathbf{C o}{ }^{\mathbf{I I}}\left(\mathbf{H}_{2} \mathbf{O}\right)_{6}$ in an alkaline aqueous medium at room temperature. Its efficiency is higher than other existing $\alpha-\mathrm{Co}(\mathrm{OH})_{2}$ based electrocatalysts operating in alkaline $\mathrm{pH}$. Moreover, the present zeolite-Y based electrocatalyst is even superior to our previously reported MOF based system Co-WOC-1 in terms of overpotential, turnover frequency and ease of synthesis. From this comprehensive study on encapsulation of $\left[\mathrm{Co}^{\mathrm{II}}\left(\mathrm{H}_{2} \mathrm{O}\right)_{6}\right]^{2+}$ in cages of zeolite- $\mathrm{Y}$, we could also infer the critical requirements for the proper mode of encapsulation. One important aspect of the work was leaching out of $\left[\mathrm{Co}^{\mathrm{II}}\left(\mathrm{H}_{2} \mathrm{O}\right)_{6}\right]^{2+}$ from zeolite-Y pores. This could happen because, the pores of zeolites are accessible through their windows, and since the diameter of windows $(7.4 \AA)$ were larger than the diameter of $\left[\mathrm{Co}^{\mathrm{II}}\left(\mathrm{H}_{2} \mathrm{O}\right)_{6}\right]^{2+}(\sim 5 \AA)$, the molecular complex could easily come out of the framework. Thus, there is a need to choose a host material, whose properties are comparable to zeolite-Y but size (diameter) of the pores/windows are smaller than that of zeolite-Y. And also we are looking for a cobalt system that works at a neutral $\mathrm{pH}$.

\subsection{Electrocatalyst: $\mathrm{Co}(\mathrm{II})$ centred POM inside the cages of ZIF-8 MOF}

Zeolitic imidazolate framework-8 (ZIF-8), a Zn ${ }^{\mathrm{II}}$-imidazolate MOF, established by Yaghi and coworkers ${ }^{58}$ (earlier prepared by Ming et al.), ${ }^{59}$ seemed to be a high potential zeolite type host material. Different research groups have shown ZIF-8 to follow a SOD topology similar to that of zeolite-Y. Like zeolites, it is also highly stable in harsh chemical conditions, wide temperature range (stable upto $200{ }^{\circ} \mathrm{C}$ ) and a wide $\mathrm{pH}$ window (from $\mathrm{pH} 0.1$ to $\mathrm{pH} 13$ ). The major structural resemblance of all these $\mathrm{Zn}^{\mathrm{II}}$-imidazolate-based compounds with zeolite earned them the name zeolitic imidazolate framework. ZIF-8 is generally prepared at an ambient temperature (ca. 20 $50{ }^{\circ} \mathrm{C}$ ), in the aqueous or methanolic medium. The synthesis usually takes $2-5$ hours for completion. In this MOF, each $\mathrm{Zn}^{\mathrm{II}}$ is tetrahedrally coordinated by four imidazolate ligands, while each imidazolate ligand coordinates to two different $\mathrm{Zn}^{\mathrm{II}}$ simultaneously. Repetition of similar structural unit completes the framework structure of ZIF-8. It has cavities of diameter $11.6 \AA$ which are accessible through windows of 


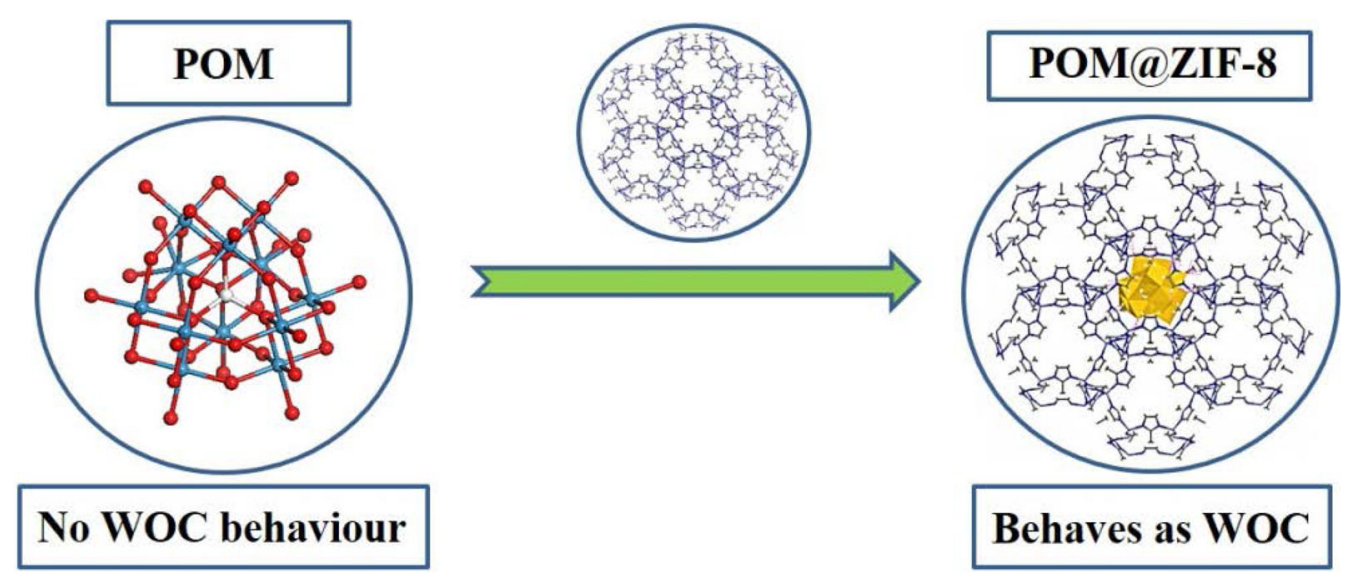

Scheme 5. Activation of Keggin $\left(\mathrm{K}_{6}\left[\mathrm{CoW}_{12} \mathrm{O}_{40}\right]\right)$ toward electrochemical water oxidation by encapsulation in ZIF-8.

diameter $3.4 \AA .{ }^{58}$ The MOF seemed to be a suitable candidate as the host material because of its (a) small sized cavities $(11.6 \AA)$ with even smaller window aperture $(3.4 \AA)$, (b) high chemical and thermal stability, (c) easy mode of synthesis, (d) scope of in situ synthesis, (i.e., the guest material can be encapsulated within the MOF during the synthesis of the latter), and (e) no electrochemical response for common solvents in the potential window of our interest. So, we chose ZIF-8 as the host material in our next work instead of zeolite-Y.

Even though, ZIF-8 is having smaller cages than those of zeolite- $\mathrm{Y}$ and size comparison between $\left[\mathrm{Co}^{\mathrm{II}}\left(\mathrm{H}_{2} \mathrm{O}\right)_{6}\right]^{2+}$ $(\sim 4.5 \AA$ ) and ZIF-8 (pore size $11.6 \AA$ and window size 3.4 $\AA$ ) suggests that ZIF-8 can be a suitable host for the species $\left[\mathrm{Co}^{\mathrm{II}}\left(\mathrm{H}_{2} \mathrm{O}\right)_{6}\right]^{2+}$, but when the encapsulation was attempted, it resulted into partial substitution of $\mathrm{Zn}^{\mathrm{II}}$ metal centers present in the framework by $\mathrm{Co}^{\mathrm{II}}$ ions. This implies, there was partial transformation of ZIF-8 ( $\mathrm{Zn}^{\mathrm{II}}$-imidazolate MOF) into ZIF-9 (CoII-imidazolate MOF), as a consequence of competition between the two metal ions to form the nodes of the framework. As the PXRD pattern (Figure S1, in Supporting Information) suggests, there was no change in the SOD topology and the inter-planner distance of ZIF due to such metal substitution. Presence of $\mathrm{Co}^{\mathrm{II}}$ in the hybrid ZIF structure could also be inferred from the colouration of ZIF-8 (colourless as such) after the attempt of $\left[\mathrm{Co}^{\mathrm{II}}\left(\mathrm{H}_{2} \mathrm{O}\right)_{6}\right]^{2+}$ encapsulation. UVVis spectrum (Figure S2, in Supporting Information) of the hybrid shows absorption maxima at $575 \mathrm{~nm}$. To determine the extent of loading/substitution ICP-AES (Figure S3, in Supporting Information) analysis was carried out. Almost half of the $\mathrm{Zn}^{\mathrm{II}}$ was substituted by $\mathrm{Co}^{\mathrm{II}}$ without affecting the crystal structure. FESEM images of this hybrid MOF showed (Figure S4, in Supporting Information File) high-quality hexagonal ZIF based crystals. Such transformation from one MOF to another by the means of metal node substitution occurring in the solid-liquid interface is highly fascinating. The hybrid MOF structure formed (a hybrid of ZIF-8 and ZIF-9) in the process, contained both metal ions but no case of proper encapsulation could be inferred.
Meanwhile, the hybrid of ZIF-8 and ZIF-9 thus prepared, was also found to be active towards electrochemical WO (Figure S5, in Supporting Information), but it degraded fast within a few hundreds of cycles of cyclic voltammetry (in the potential window $0.05 \mathrm{~V}$ to $1.4 \mathrm{~V}$ ) in neutral $\mathrm{pH}$ and could not operate in a catalytic manner.

Rationalizing these results, the necessity to search for a suitable guest, was crucial to use ZIF-8 as the host material. In this regard, foremost structural requirements for successful encapsulation are (a) size match between ZIF-8 and guest as explained earlier, (b) the guest entity must hold the $\mathrm{Co}^{\mathrm{II}}$ (active metal ion) in a rigid coordinational environment. $\mathrm{Co}^{\mathrm{II}}$-based Keggin $\mathrm{K}_{6}\left[\mathrm{CoW}_{12} \mathrm{O}_{40}\right]$ seemed to be a good choice as a guest system (Scheme 5). Keggins are the most stable structural variant of all polyoxometalates. Different polyoxometalate based compound are well-established as efficient catalysts towards organic reactions, photocatalytic and electrocatalytic water oxidation, proton reduction and oxygen reduction reactions. ${ }^{60-64}$ Such wide field of application, notable stability and many other properties have contributed to our fascination with choosing a Keggin polyoxometalate based guest species in this case. $\left[\mathrm{CoW}_{12} \mathrm{O}_{40}\right]^{6-}$ has a $\mathrm{Co}^{\mathrm{II}}$ at the center which is tetrahedrally surrounded by four $\left\{\mathrm{W}_{3} \mathrm{O}_{10}\right\}$ interconnected subunits (Scheme 5). Due to the complete inorganic structure, polyoxometalates are capable of fast electron transport. The distance between peripheral oxygen atoms of $\mathrm{K}_{6}\left[\mathrm{CoW}_{12} \mathrm{O}_{40}\right]$ is $10.6 \AA$, which is larger than the window aperture $(3.4 \AA)$ of ZIF-8 but is smaller than the cavity diameter (11.6 $⿱$ A). Thus, we chose to employ $\mathrm{K}_{6}\left[\mathrm{CoW}_{12} \mathrm{O}_{40}\right]$ as the guest material.

There was no alteration in the crystal planes of ZIF-8 after encapsulation of $\left[\mathrm{CoW}_{12} \mathrm{O}_{40}\right]^{6-}$, as confirmed from PXRD. Similarly, from PXRD, we found that POM@ZIF-8 is stable in wide $\mathrm{pH}$ range ( $\mathrm{pH} 1$ to $\mathrm{pH} 14$ ) and harsh chemical conditions. ${ }^{49}$ From cyclic voltammetric analysis (1000 cycles of cyclic voltammetric scans), the composite was found to be highly stable under operational electrochemical conditions as well. While interestingly, $\mathrm{K}_{6}\left[\mathrm{CoW}_{12} \mathrm{O}_{40}\right]$, the guest precursor of the composite is not stable in neutral $\mathrm{pH}$ under the 


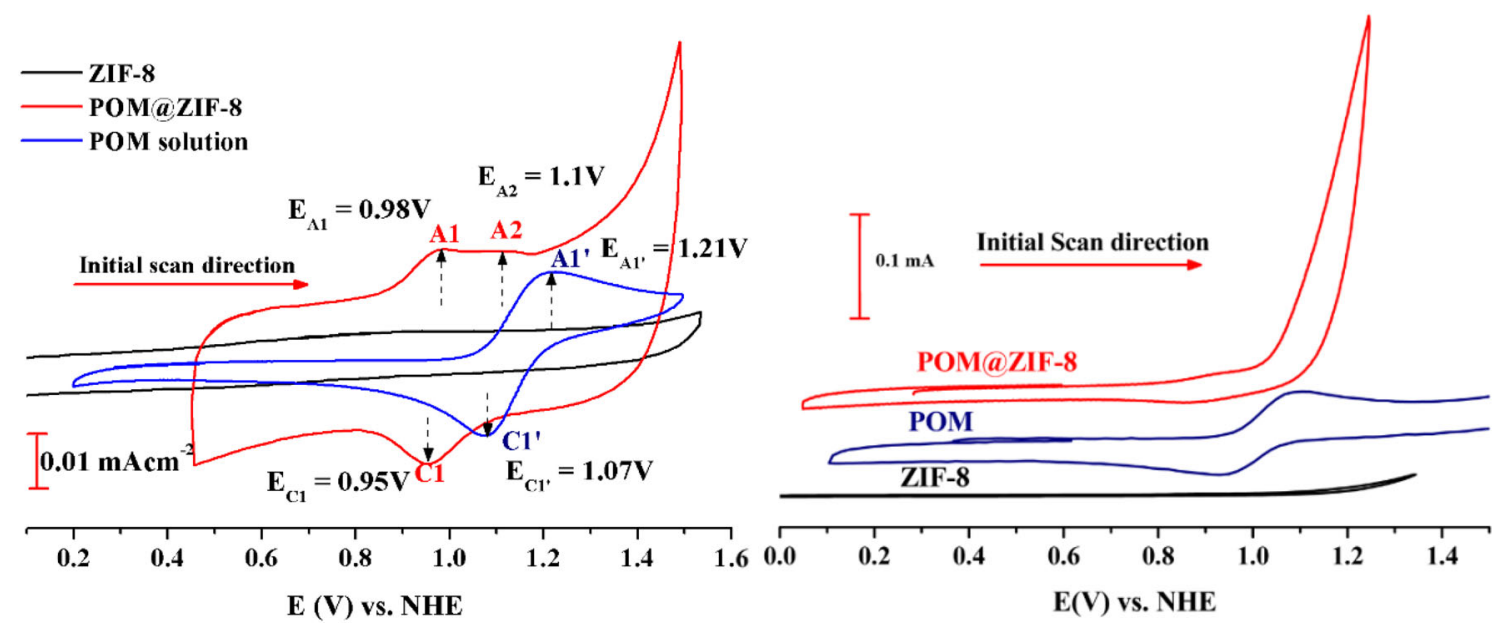

Figure 7. (a) Cyclic voltammograms of ZIF-8, POM@ZIF-8 (both were insoluble and were coated on glassy carbon electrode) and POM $\left(\mathrm{K}_{6}\left[\mathrm{CoW}_{12} \mathrm{O}_{40}\right]\right)$ dissolved in aqueous solution (0.01 M). 0.1 $\mathrm{M} \mathrm{Na}_{2} \mathrm{SO}_{4}$ solution of $\mathrm{pH} 1.9$ was used as supporting electrolyte. $\mathrm{pH}$ was adjusted by $0.1 \mathrm{M} \mathrm{H}_{2} \mathrm{SO}_{4}$ solution. (b) Cyclic voltammograms of ZIF-8, POM@ZIF-8 (both were insoluble and were coated on glassy carbon electrode) and POM $\left(\mathrm{K}_{6}\left[\mathrm{CoW}_{12} \mathrm{O}_{40}\right]\right)$ dissolved in aqueous solution $(0.01 \mathrm{M})$. $0.1 \mathrm{M} \mathrm{Na}_{2} \mathrm{SO}_{4}$ solution (neutral pH) was used as supporting electrolyte. Adapted from our earlier work by Mukhopadhyay et al. ${ }^{49}$

potential applied for water oxidation. Thus, it can be inferred that not only the primary difficulty that we faced in our earlier work with the stability issue of the composite was solved in this study, but the encapsulation of $\mathrm{H}_{6}\left[\mathrm{CoW}_{12} \mathrm{O}_{40}\right]$ in ZIF8 actually enhanced its robustness in comparison to that of $\mathrm{K}_{6}\left[\mathrm{CoW}_{12} \mathrm{O}_{40}\right]$ itself.

All the electrochemical analysis of POM@ZIF-8 was carried out in neutral $\mathrm{pH}$ if not mentioned otherwise. The compound was insoluble in common solvents. Thus, the electrochemical analysis was carried out in a heterogeneous manner following a procedure similar to the one explained earlier for Co-WOC-1. Cyclic voltammograms of POM@ZIF-8, ZIF-8 (both in a heterogeneous manner) and $1 \mathrm{mM}$ solution of $\mathrm{K}_{6}\left[\mathrm{CoW}_{12} \mathrm{O}_{40}\right]$ (in a homogeneous manner) were recorded in different $\mathrm{pH}$ (from acidic $\mathrm{pH}$ to neutral $\mathrm{pH}$ ). No redox response was observed for ZIF-8 in any $\mathrm{pH}$ within the potential window of our interest. A quasireversible couple $\left(\mathrm{Al}^{\prime} / \mathrm{Cl}^{\prime}\right)$ corresponding to $\mathrm{Co}{ }^{\mathrm{III}} / \mathrm{Co}^{\mathrm{II}}$ (with $\left.\mathrm{E}_{1 / 2\left(\mathrm{Al}^{\prime} / \mathrm{Cl}^{\prime}\right)}=1.14 \mathrm{~V}\right)$ is clearly visible for Keggin $\left(\mathrm{K}_{6}\left[\mathrm{CoW}_{12} \mathrm{O}_{40}\right]\right)$ at pH 1.9 (Figure 7a). In case of POM@ZIF$8\left(\mathrm{H}_{6}\left[\mathrm{CoW}_{12} \mathrm{O}_{40}\right] @ \mathrm{ZIF}-8\right)$, the $\mathrm{Co}^{\mathrm{III}} / \mathrm{Co}^{\mathrm{II}}$ couple was shifted to $0.97 \mathrm{~V}$ (Figure $7 \mathrm{a}$ ). The shift in $\mathrm{Co}^{\mathrm{III}} / \mathrm{Co}^{\mathrm{II}}$ position in cyclic voltammogram of POM@ZIF-8 from the $\mathrm{Co}^{\mathrm{III}} / \mathrm{Co}^{\mathrm{II}}$ position of $\mathrm{K}_{6}\left[\mathrm{CoW}_{12} \mathrm{O}_{40}\right]$ is vital, because, such shift is a direct consequence of the increase in electron accessibility around the central $\mathrm{Co}^{\mathrm{II}}$ of $\left[\mathrm{CoW}_{12} \mathrm{O}_{40}\right]^{6-}$. This increase in electron accessibility stabilizes the $\mathrm{Co}^{\text {III }}$ state easily and so, less anodic potential becomes sufficient for $\mathrm{Co}^{\mathrm{II}} \rightarrow \mathrm{CO}^{\mathrm{III}}$ conversion. This result proves another added advantage of encapsulation. Apart from the increased robustness of $\left(\mathrm{H}_{6}\left[\mathrm{CoW}_{12} \mathrm{O}_{40}\right]\right)$ inside ZIF-8, this fascinating peak shift for the $\mathrm{Co} \mathrm{OII}^{\mathrm{II}} / \mathrm{Co}^{\mathrm{II}} \mathrm{cou}-$ ple points towards electronic redistribution occurring in the guest species, resulting in an enhancement of electron density in $\mathrm{H}_{6}\left[\mathrm{CoW}_{12} \mathrm{O}_{40}\right]$. Cyclic voltammograms (Figure $7 \mathrm{~b}$ ) in neutral $\mathrm{pH}$ clearly show a lowering of $\mathrm{Co}^{\mathrm{III}} / \mathrm{Co}^{\mathrm{II}}$ potential in case of POM $\left(\mathrm{K}_{6}\left[\mathrm{CoW}_{12} \mathrm{O}_{40}\right]\right)$ as well as POM@ZIF$8\left(\mathrm{H}_{6}\left[\mathrm{CoW}_{12} \mathrm{O}_{40}\right] @ \mathrm{ZIF}-8\right)$, as compared to acidic pH. A prominent onset of current was observed in the cyclic voltammogram of POM@ZIF-8 due to water oxidation (reasons explained earlier) after the $\mathrm{CO}{ }^{\mathrm{III}} / \mathrm{CO}^{\mathrm{II}}$ couple position. Water oxidation by POM@ZIF-8 was facilitated at neutral pH, which states its higher efficiency as WOC in neutral $\mathrm{pH}$. There was no electrochemical response in case of ZIF-8 at neutral $\mathrm{pH}$. To interpret the cyclic voltammetric results, we focused towards a better understanding of the structural aspects of POM@ZIF-8 in comparison to Keggin POM with the help of different characterization techniques starting from UV-Vis spectroscopy, FT-IR spectroscopy, X-Ray photoelectron spectroscopy and other characterization techniques. $\mathrm{W}_{4 \mathrm{f}} \mathrm{X}$-ray photoelectron spectra of $\mathrm{K}_{6}\left[\mathrm{CoW}_{12} \mathrm{O}_{40}\right]$ and $\mathrm{H}_{6}\left[\mathrm{CoW}_{12} \mathrm{O}_{40}\right] @ \mathrm{ZIF}-8$ (Figure 8 ) showed a lowering of binding energy of tungsten in case of POM@ZIF-8 from that of Keggin compound itself. This infers an electronic enhancement in tungsten centered molecular orbitals of the Keggin. Besides, FTIR spectrum of POM@ZIF-8 was found to have some shifted peaks as well as some newly developed peaks when compared to that of either Keggin $\left(\mathrm{K}_{6}\left[\mathrm{CoW}_{12} \mathrm{O}_{40}\right]\right)$ or ZIF-8 as such. This suggests some interactions between the host and the guest moiety in case of POM@ZIF-8 which can cause this kind of shift in the peak positions. UV-Vis spectrum of POM@ZIF-8 $\left(\mathrm{H}_{6}\left[\mathrm{CoW}_{12} \mathrm{O}_{40}\right]\right.$ @ZIF-8) also indicates such interactions taking place. Thus, we could infer from all these spectroscopic techniques that, there must be some interaction between peripheral atoms of the guest moiety and inner surface of ZIF-8. These interactions result in an increment in electronic density around $\mathrm{H}_{6}\left[\mathrm{CoW}_{12} \mathrm{O}_{40}\right]$ species. We logically assume these interactions to take place between the delocalized $\pi$-electron clouds of imidazolate rings in ZIF-8 


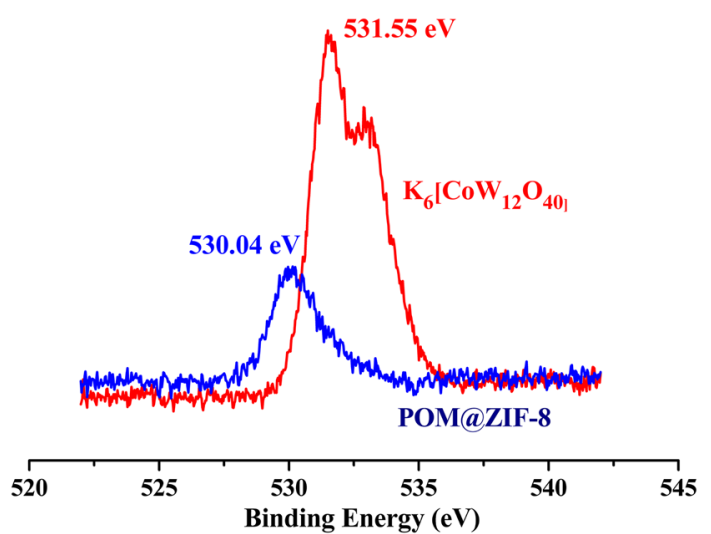

Figure 8. XPS spectra of $\mathrm{W}_{4 \mathrm{f}}$ in Keggin $\left(\mathrm{K}_{6}\left[\mathrm{CoW}_{12} \mathrm{O}_{40}\right]\right)$ and POM@ZIF-8. Adapted from our earlier work by Mukhopadhyay et al. ${ }^{49}$

and the low lying vacant LUMOs of tungsten atoms in the POM. This helps in lowering of the potential requirement of $\mathrm{Co}^{\mathrm{III}} / \mathrm{Co}^{\mathrm{II}}$ in POM@ZIF-8. This positive effect of encapsulation is a crucial aspect of the work.

As explained already, POM@ZIF-8 was found to be robust electrocatalyst for $\mathrm{WO}$ reaction in neutral $\mathrm{pH}$. Thus, we were interested in understanding its water oxidation mechanism and kinetics. From galvanostatic iR-corrected Tafel plot, we could find high overpotential (' $\eta$ ') of $784.19 \mathrm{mV}$ to be required for a current density (j) of $1 \mathrm{mAcm}^{-2}$. Tafel slope was also found to be high $(783.62 \mathrm{mV} /$ decade $)$ due to resistive nature of the ZIF-8 framework. This factor results in high Ohmic resistance, which might reduce the conductivity within the framework's interior. Thus, the high overpotential requirement of the catalyst can be attributed to a cumulative effect of low loading of POM in MOF ( 1 in every 6 cages) and slow mass transfer within the pores of ZIF-8. WOC behavior of POM@ZIF-8 was found to be $\mathrm{pH}$ dependent. A plot of applied potential $v s . \mathrm{pH}$ at a fixed current density $\left(0.2 \mathrm{mAcm}^{-2}\right) \mathrm{sug}-$ gests a proton-coupled electron transfer (PCET) mechanism to be involved in POM@ZIF-8 catalyzed WO. ${ }^{49}$ Again, normalized current density (with respect to scan rate) for the catalytic WO decreases with increasing scan rate in case of POM@ZIF-8, suggesting the involvement of a chemical process as rate limiting step, which is most likely to be ' $\mathrm{O}-\mathrm{O}$ ' bond formation.

Although we were not able to suggest an exact mechanism for the WO catalysis by POM@ZIF-8, we presume the water molecules to get associated through hydrogen bonding with Keggin cluster somewhere on its surface similar to many other polyoxometalates. ${ }^{65-68}$ Structural properties of the Keggin and evidences of some of its organic reaction catalysis from literature encouraged us for such logical consideration. A detailed look at the organic reaction catalysis suggests that the bulky organic substrate can never reach the central cobalt atom of the Keggin. In spite of no direct bonding of the substrate organic moiety with the true catalytic center i.e., the cobalt center, the reaction (e.g., oxidation/reduction reactions of the organic substrate) proceeds successfully. ${ }^{69,70}$
Similarly, in case of Keggin-catalyzed water oxidation, a parallel mechanism can be feasible without disturbing the tetrahedral disposition of the central cobalt. Such association can allow facile electron transport between Keggin and water molecules. Though the widely accepted mode of initiation of electrochemical WO is through coordinate binding of the water molecule directly to the active site, but recently, Chen and his co-workers, ${ }^{71}$ have probed photocatalytic $\mathrm{WO}$ by $\mathrm{TiO}_{2}$ and have shown that WO is assisted by dual hydrogen bonding structure over the conventional mode of initiation of WO. Thus, we feel, similar will be the case for POM@ZIF-8-catalyzed electrochemical WO. Faradaic efficiency of POM@ZIF-8 was evaluated by determining the amount of $\mathrm{O}_{2}$ evolved in constant current coulometry (at $\mathrm{j}=1 \mathrm{mAcm}^{-2}$ ) and was found to be $95.7 \%$. Turnover frequencies (TOF) were calculated from the quantitative oxygen evolution (TOF $=12.5 \mathrm{~s}^{-1}$ ) and also from electrochemical measurements (TOF $=10.19 \mathrm{~s}^{-1}$ ) (using Tafel plot and calculated surface coverage value). Such high TOF is extremely rare among all electrocatalytic WOC reported. Thus, it can be said that the requirement of very high overpotential is the most serious drawback of POM@ZIF-8 as an electrochemical WOC, while the other factors, i.e., Faradic efficiency, turnover frequency, recyclability, robustness, etc., prove the potential of such POM encapsulated MOF systems to perform electrocatalytic water oxidation.

\section{Conclusions}

In conclusion, it can be said that in this article, we have explained the vital factors that affect the stability of the guest entity inside the cavity of the porous host (i.e., zeolites, MOFs, etc). The most crucial factor to prepare stable host-guest type electrocatalytic water oxidation catalyst is the size match between (a) guest molecule, (b) pore size of the host (bigger than the guest molecule) and (c) access through window aperture of the host (smaller than the guest molecule). If the required size match criterion is not satisfied, the guest species can leach out resulting in a partial or complete loss of catalytic activity of the composite material. Such leaching can also result in the formation of heterogeneous metal oxides/hydroxides depending upon the operational potential and $\mathrm{pH}$. Successful encapsulation following all the three factors mentioned above provides the guest species mechanical as well as chemical robustness. Apart from the gain in stability, in certain cases, there can be some interaction between the guest and the host species resulting in an enhancement of electrocatalytic water oxidation activity of the guest species. Such interactions are the added advantages of designing electrocatalysts based on host-guest chemistry. This is a relatively unexplored field of preparation of electrocatalytic water oxidation catalysts and it seems to have 
endless potential depending upon the choice of the guest and the host species.

\section{Supplementary Information (SI)}

Supplementary Information contains the general methods involved in electrochemical measurements, overpotential calculations from Tafel plot, turnover frequency calculation, Faradic efficiency calculation, and discussion on $\mathrm{Co}^{\mathrm{II}}$ (as a part of the framework) in ZIF-8, including relevant figures. Supplementary Information is available at www.ias.ac. in/chemsci.

\section{Acknowledgements}

We thank SERB, Department of Science and Technology, Government of India, for financial support (Project No. EMR/2017/002971). We acknowledge support by UGS-CAS, DST-PURSE and DST-FIST schemes. OB and SM thank UGC and DST INSPIRE for their fellowships. We are grateful to MTIC 2017 organizing committee for this invitation.

\section{References}

1. Blakemore J D, Crabtree R H and Brudvig G W 2015 Molecular catalysts for water oxidation Chem. Rev. 115 12974

2. Vinyard D J, Ananyev G M and Dismukes G C 2013 Photosystem II: the reaction center of oxygenic photosynthesis Annu. Rev. Biochem. 82577

3. Lewis N S and Nocera D G 2006 Powering the planet: chemical challenges in solar energy utilization Proc. Natl. Acad. Sci. USA 10315729

4. Kanan M W and Nocera D G 2008 In situ formation of an oxygen-evolving catalyst in neutral water containing phosphate and $\mathrm{Co}^{2+}$ Science 3211072

5. Hunter B M, Gray H B and Müller A M 2016 Earthabundant heterogeneous water oxidation catalysts Chem. Rev. 11614120

6. Schmidt-Rohr K 2015 Why combustions are always exothermic, yielding about $418 \mathrm{~kJ}$ per mole of $\mathrm{O}_{2} \mathrm{~J}$. Chem. Educ. 922094

7. Symes M D, Surendranath Y, Lutterman D A and Nocera D G 2011 Bidirectional and unidirectional PCET in a molecular model of a cobalt-based oxygen-evolving catalyst J. Am. Chem. Soc. 1335174

8. Surendranath Y, Kanan M W and Nocera D G 2010 Mechanistic studies of the oxygen evolution reaction by a cobalt-phosphate catalyst at neutral $\mathrm{pH}$ J. Am. Chem. Soc. 13216501

9. Fukuzumi S and Hong D 2014 Homogeneous versus heterogeneous catalysts in water oxidation Eur. J. Inorg. Chem. 2014645

10. Diaz-Morales O, Calle-Vallejo F, de Munck C and Koper M T M 2013 Electrochemical water splitting by gold: evidence for an oxide decomposition mechanism Chem. Sci. 42334
11. Minguzzi A, Lugaresi O, Achilli E, Locatelli C, Vertova A, Ghigna P and Rondinini S 2014 Observing the oxidation state turnover in heterogeneous iridium-based water oxidation catalysts Chem. Sci. 53591

12. Matheu R, Francàs L, Chernev P, Ertem M Z, Batista V, Haumann M, Sala X and Llobet A 2015 Behavior of the Ru-bda water oxidation catalyst covalently anchored on glassy carbon electrodes ACS Catal. 53422

13. Sheehan S W, Thomsen J M, Hintermair U, Crabtree R H, Brudvig G W and Schmuttenmaer C A 2015 A molecular catalyst for water oxidation that binds to metal oxide surfaces Nat. Commun. 66469

14. Abe T, Nagai K, Kabutomori S, Kaneko M, Tajiri A and Norimatsu T 2006 An organic photoelectrode working in the water phase: visible-light-induced dioxygen evolution by a perylene derivative/cobalt phthalocyanine bilayer Angew. Chem. Int. Ed. Engl. 452778

15. Dogutan D K, McGuire R and Nocera D G 2011 Electocatalytic water oxidation by cobalt(III) hangman $\beta$-octafluoro corroles J. Am. Chem. Soc. 1339178

16. Nakazono T, Parent A R and Sakai K 2013 Cobalt porphyrins as homogeneous catalysts for water oxidation Chem. Commun. 496325

17. Wang D and Groves J T 2013 Efficient water oxidation catalyzed by homogeneous cationic cobalt porphyrins with critical roles for the buffer base Proc. Natl. Acad. Sci. USA 11015579

18. Ryota Terao, Takashi Nakazono, Alexander Rene Parent and Ken Sakai 2016 Photochemical water oxidation catalysed by a water-soluble copper phthalocyanine ChemPlusChem 811064

19. Nakazono T, Parenta A R and Sakai K 2013 Cobalt porphyrins as homogeneous catalysts for water oxidation Chem. Commun. 496325

20. Lei H, Han A, Li F, Zhang M, Han Y, Du P, Lai W and Cao R 2014 Electrochemical, spectroscopic and theoretical studies of a simple bifunctional cobalt corrole catalyst for oxygen evolution and hydrogen production Phys. Chem. Chem. Phys. 161883

21. Jia H, Yao Y, Gao Y, Lu D and Du P 2016 Pyrolyzed cobalt porphyrin-based conjugated mesoporous polymers as bifunctional catalysts for hydrogen production and oxygen evolution in water Chem. Commun. 52 13483

22. Huang Z, Luo Z, Geletii Y V, Vickers J W, Yin Q, Wu D, Hou Y, Ding Y, Song J, Musaev D G, Hill C L and Lian T 2011 Efficient light-driven carbon-free cobalt-based molecular catalyst for water oxidation J. Am. Chem. Soc. 1332068

23. Blasco-Ahicart M, Soriano-López J, Carbó J J, Poblet J M and Galan-Mascaros J R 2017 Polyoxometalate electrocatalysts based on earth-abundant metals for efficient water oxidation in acidic media Nat. Chem. 1024

24. Song F, Ding Y, Ma B, Wang C, Wang Q, Du X, Fua S and Song J $2013 \mathrm{~K}_{7}\left[\mathrm{Co}^{\mathrm{III}} \mathrm{Co}^{\mathrm{II}}\left(\mathrm{H}_{2} \mathrm{O}\right) \mathrm{W}_{11} \mathrm{O}_{39}\right]$ : a molecular mixed-valence Keggin polyoxometalate catalyst of high stability and efficiency for visible light-driven water oxidation Energy Environ. Sci. 61170

25. Folkman S J, Kirner J T and Finke R G 2016 Cobalt polyoxometalate $\mathrm{Co}_{4} \mathrm{~V}_{2} \mathrm{~W}_{18} \mathrm{O}_{68}^{10-}$ : a critical investigation of its synthesis, purity, and observed ${ }^{51} \mathrm{~V}$ quadrupolar NMR Inorg. Chem. 555343 
26. Folkman S J and Finke R G 2017 Electrochemical water oxidation catalysis beginning with $\mathrm{Co}$ (II) polyoxometalates: the case of the precatalyst $\mathrm{Co}_{4} \mathrm{~V}_{2} \mathrm{~W}_{18} \mathrm{O}_{68}^{10-} A C S$ Catal. 77

27. Artero V and Fontecave M 2013 Solar fuels generation and molecular systems: is it homogeneous or heterogeneous catalysis? Chem. Soc. Rev. 422338

28. El Wakkad S E S and Hickling A 1950 The anodic behaviour of metals. Part VI.-Cobalt Trans. Faraday Soc. 46820

29. Pandey A D, Jia C, Schmidt W, Leoni M, Schwickardi M, Schüth F and Weidenthaler C 2012 Size-controlled synthesis and microstructure investigation of $\mathrm{Co}_{3} \mathrm{O}_{4}$ nanoparticles for low-temperature CO oxidation J. Phys. Chem. C 11619405

30. Gardner G P, Go Y B, Robinson D M, Smith P F, Hadermann J, Abakumov A, Greenblatt $M$ and Dismukes $G$ C 2012 Structural requirements in lithium cobalt oxides for the catalytic oxidation of water Angew. Chem. Int. Ed. 511616

31. Song F and Hu X 2014 Ultrathin cobalt-manganese layered double hydroxide is an efficient oxygen evolution catalyst J. Am. Chem. Soc. 13616481

32. Dey S, Mondal B and Dey A 2014 An acetate bound cobalt oxide catalyst for water oxidation: role of monovalent anions and cations in lowering overpotential Phys. Chem. Chem. Phys. 1612221

33. Bose S, Debgupta J, Ramsundar R M and Das S K 2017 Electrochemical water oxidation catalyzed by an in situ generated $\alpha-\mathrm{Co}(\mathrm{OH})_{2}$ film on Zeolite-Y surface Chem. Eur. J. 238051

34. Chatterjee S, Sengupta K, Hematian S, Karlin K D and Dey A 2015 Electrocatalytic $\mathrm{O}_{2}$ reduction by synthetic cytochrome c oxidase mimics: identification of a "Bridging" Peroxo intermediate involved in facile $4 \mathrm{e}^{-} / 4 \mathrm{H}^{+} \mathrm{O}_{2}$-reduction J. Am. Chem. Soc. 137 12897

35. Amanullah S, Das P K, Samanta S and Dey A 2015 Tuning the thermodynamic onset potential of electrocatalytic $\mathrm{O}_{2}$ reduction reaction by synthetic iron-porphyrin complexes Chem. Commun. 5110010

36. Mahammed A, Mondal B, Rana A, Dey A and Gross Z 2014 The cobalt corrole catalyzed hydrogen evolution reaction: surprising electronic effects and characterization of key reaction intermediates Chem. Commun. 50 2725

37. Mondal B, Sengupta K, Rana A, Mahammed A, Botaoshansky M, Ghosh Dey S, Gross Z and Dey A 2013 Cobalt corrole catalyst for efficient hydrogen evolution reaction from $\mathrm{H}_{2} \mathrm{O}$ under ambient conditions: reactivity, spectroscopy, and density functional theory calculations Inorg. Chem. 523381

38. Nocera D G 2012 The artificial leaf Acc. Chem. Res. 45 767

39. Jiao F and Frei H 2009 Nanostructured cobalt oxide clusters in mesoporous silica as efficient oxygen-evolving catalysts Angew. Chem. Int. Ed. 481841

40. Guo S -X, Liu Y, Lee C -Y, Bond A M, Zhang J, Geletii Y V and Hill C L 2013 Graphene-supported $\left[\left\{\mathrm{Ru}_{4} \mathrm{O}_{4}(\mathrm{OH})_{2}\left(\mathrm{H}_{2} \mathrm{O}\right)_{4}\right\}\left(\gamma-\mathrm{SiW}_{10} \mathrm{O}_{36}\right)_{2}\right]^{10-}$ for highly efficient electrocatalytic water oxidation Energy Environ. Sci. 62654
41. Gao M R, Cao X, Gao Q, Xu Y F, Zheng Y R, Jiang J and Yu S H 2014 Nitrogen-doped graphene supported $\mathrm{CoSe}_{2}$ nanobelt composite catalyst for efficient water oxidation ACS Nano 83970

42. Bhaskar A, Banerjee R and Kharul U 2014 ZIF-8@PBIBuI composite membranes: eloquent effects of PBI structural variations towards gas permeation performance $J$. Mater. Chem. A 212962

43. Palaniselvam T, Biswal B P, Banerjee R and Kurungot S 2013 Zeolitic imidazolate frameworks (ZIFs) derived hollow core-nitrogen doped carbon nanostructures for oxygen reduction reactions in PEFCs Chem. Eur. J. 19 9335

44. Aiyappa H B, Thote J, Shinde D B, Banerjee R and Kurungot S 2016 Cobalt-modified covalent organic framework as a robust water oxidation electrocatalyst Chem. Mater. 284375

45. Nepal B and Das S 2013 Sustained water oxidation by a catalyst cage-isolated in a metal-organic framework Angew. Chem. Int. Ed. 527224

46. Han J, Wang D, Du Y H, Xi S, Chen Z, Yin S, Zhou T and $\mathrm{Xu}$ R 2016 Polyoxometalate immobilized in MIL$101(\mathrm{Cr})$ as an efficient catalyst for water oxidation Appl. Catal. A Gen. $\mathbf{5 2 1} 83$

47. Brunschwig B S, Chou M H, Creutz C, Ghosh P and Sutin N 1983 Mechanisms of water oxidation to oxygen: cobalt(IV) as an intermediate in the aquocobalt(II)catalyzed reaction J. Am. Chem. Soc. 1054832

48. Manna P, Debgupta J, Bose S and Das S K 2016 A mononuclear $\mathrm{Co}^{\Pi}$ coordination complex locked in a confined space and acting as an electrochemical wateroxidation catalyst: a "ship-in-a-bottle" approach Angew. Chem. Int. Ed. $\mathbf{5 5} 2425$

49. Mukhopadhyay S, Debgupta J, Singh C, Kar A and Das S K 2018 A Keggin polyoxometalate shows water oxidation activity at neutral pH: POM@ZIF-8, an efficient and robust electrocatalyst Angew. Chem. Int. Ed. 571918

50. Manna P, Tripuramallu B K, Bommakanti S and Das S K 2015 Synthesis, characterization and magnetism of metal-organic compounds: role of positions of the coordinating groups of a meso-flexible ligand in placing anisotropy to exhibit spin-canting behaviour Dalton Trans. 442852

51. Manna P and Das S K 2015 A perceptive approach in assessing rigidity versus flexibility in the construction of diverse metal-organic coordination networks: synthesis, structure and magnetism Cryst. Growth Des. 151407

52. Zhang M -T, Chen Z, Kang P and Meyer T J 2013 Electrocatalytic water oxidation with a copper(II) polypeptide complex J. Am. Chem. Soc. 1352048

53. Weinberg D R, Gagliardi C J, Hull J F, Murphy C F, Kent C A, Westlake B C, Paul A, Ess D H, McCafferty D G and Meyer T J 2012 Proton-coupled electron transfer Chem. Rev. 1124016

54. Wu L and Navrotsky A 2016 Synthesis and thermodynamic study of transition metal ion $\left(\mathrm{Mn}^{2+}, \mathrm{Co}^{2+}, \mathrm{Cu}^{2+}\right.$, and $\mathrm{Zn}^{2+}$ ) exchanged zeolites A and Y Phys. Chem. Chem. Phys. 1810116

55. Jiang Y, Li X, Wang T and Wang C 2016 Enhanced electrocatalytic oxygen evolution of $\alpha-\mathrm{Co}(\mathrm{OH})_{2}$ nanosheets on carbon nanotube/polyimide films Nanoscale $\mathbf{8}$ 9667 
56. Kim H, Kim Y, Noh Y and Kim W B 2016 Ultrathin amorphous $\alpha-\mathrm{Co}(\mathrm{OH})_{2}$ nanosheets grown on $\mathrm{Ag}$ nanowire surfaces as a highly active and durable electrocatalyst for oxygen evolution reaction Dalton Trans. 45 13686

57. Lu X F, Liao P Q, Wang J W, Wu J X, Chen X W, He C T, Zhang J P, Li G R and Chen X M 2016 An alkaline-stable, metal hydroxide mimicking metal-organic framework for efficient electrocatalytic oxygen evolution $J$. Am. Chem. Soc. 1388336

58. Banerjee R, Phan A, Wang B, Knobler C, Furukawa H, O'Keeffe M and Yaghi O M 2008 High-throughput synthesis of zeolitic imidazolate frameworks and application to $\mathrm{CO}_{2}$ capture Science 319939

59. Huang X-C, Lin Y-Y, Zhang J-P and Chen X-M 2006 Ligand-directed strategy for zeolite-type metal-organic frameworks: zinc(II) imidazolates with unusual zeolitic topologies Angew. Chem. Int. Ed. 451557

60. Kumar A, Gupta A K, Devi M, Gonsalves K E and Pradeep C P 2017 Engineering multi-functionality in hybrid polyoxometalates: aromatic sulfonium octamolybdates as excellent photochromic materials and self-separating catalysts for epoxidation Inorg. Chem. 5610325

61. Reddy P G, Mamidi M and Pradeep C P 2016 An organic inorganic hybrid supramolecular framework material based on $\left[\mathrm{P}_{2} \mathrm{~W}_{18} \mathrm{O}_{62}\right]^{6-}$ cluster and $\mathrm{Yb}$ and $\mathrm{Na}$ complexes of pyridine 2,6-dicarboxylic acid: a catalyst for selective oxidation of sulfides in water with $\mathrm{H}_{2} \mathrm{O}_{2}$ CrystEngComm 184272

62. Kalyani V, Satyanarayana V S V, Singh V, Pradeep C P, Ghosh S, Sharma S K and Gonsalves K E 2015 New polyoxometalates containing hybrid polymers and their potential for nano-patterning Chem. Eur. J. 212250

63. Das S, Kumar S, Garai S, Pochamoni R, Paul S and Roy S 2017 Softoxometalate $\left[\left\{\mathrm{K}_{6.5} \mathrm{Cu}(\mathrm{OH})_{8.5}\left(\mathrm{H}_{2} \mathrm{O}\right)_{7.5}\right\}_{0.5} @ \mathrm{~K}_{3} \mathrm{PW}_{12} \mathrm{O}_{40}\right] \mathrm{n}(\mathrm{n}=1348$
-2024) as an efficient inorganic material for $\mathrm{CO}_{2}$ reduction with concomitant water oxidation ACS Appl. Mater. Interfaces 935086

64. Das S, Biswas S, Balaraju T, Barman S, Pochamoni $\mathrm{R}$ and Roy S 2016 Photochemical reduction of carbon dioxide coupled with water oxidation using various softoxometalate (SOM) based catalytic systems J. Mater. Chem. A 48875

65. Liu H, Sun Y, Chen Y-G, Meng F-X and Shi D-M 2008 Syntheses, structures and properties of three neutral bisupporting heteropolyoxometalates J. Coord. Chem. 613102

66. Dec S F and Herring A M 2004 Structure and dynamics of disodium hydrogen 12-tungstophosphoric acid J. Phys. Chem. B 10812339

67. Wang X, Kong C-Y, Lai J-J and Wei M-L 2016 Synthesis, structure and proton conductivity of a complex based on decorated Keggin-type cluster: $\left\{\left[\mathrm{Cu}(\mathrm{dmbipy})\left(\mathrm{H}_{2} \mathrm{O}\right)_{2} \mathrm{Cl}_{0.5}\right]_{2}\left[\mathrm{PW}_{12} \mathrm{O}_{40}\right]\right\} \cdot 7 \mathrm{H}_{2} \mathrm{O}$ (dmbipy=4,4'-dimethyl-2,2/-bipyridine) J. Cluster Sci. 27645

68. Ftini M M and Haddad A 2014 Hydrothermal synthesis and crystal structure of an inorganic-organic hybrid heteropolymolybdate $\left(\mathrm{C}_{4} \mathrm{H}_{16} \mathrm{~N}_{3}\right)_{2}\left[\mathrm{NiMo}_{2} \mathrm{O}_{40}\right] \mathrm{Cl}_{2} \cdot 9 \mathrm{H}_{2} \mathrm{O}$ Crystallogr. Crystallogr. Rep. 59949

69. Li X and Zhang Y 2016 Oxidative dehydration of glycerol to acrylic acid over vanadium-substituted cesium salts of Keggin-type heteropolyacids ACS Catal. 62785

70. Zhao X, Duan Y, Yang F, Wei W, Xu Y and Hu C 2017 Efficient mechanochemical synthesis of polyoxometalate $\subset$ ZIF complexes as reusable catalysts for highly selective oxidation Inorg. Chem. 5614506

71. Sheng H, Zhang H, Song W, Ji H, Ma W, Chen C and Zhao J 2015 Activation of water in titanium dioxide photocatalysis by formation of surface hydrogen bonds: an in situ IR spectroscopy study Angew. Chem. Int. Ed. 54 5905 